\title{
Smads and early developmental signaling by the TGF $\beta$ superfamily
}

\author{
Malcolm Whitman ${ }^{1}$ \\ Department of Cell Biology, Harvard M edical School, Boston, Massachusetts 02115 USA
}

Members of the transforming growth factor $\beta$ (TGF $\beta$ ) superfamily of peptide growth factors regulate a broad range of cellular functions, including prol iferation, apoptosis, extracellular matrix secretion and adhesion, terminal differentiation, and specification of developmental fate (Roberts and Sporn 1993; Wall and Hogan 1994; M oses and Serra 1996). Although regulation of each of these functions by TGF $\beta$ superfamily factors is important throughout embryonic development, it is the potency of these factors in regulating developmental fate that has been the focus of recent excitement among embryologists. This has been primarily because of indications in both vertebrate and invertebrate model systems that TGF $\beta$ s can serve as morphogens, acting across developing tissues in a graded fashion to specify a patterned array of cell fates (Gurdon et al. 1994; N ellen et al. 1996; N eumann and Cohen 1997). A defining feature of morphogens is their ability to specify multiple cell types over a range of concentrations. This capacity has been demonstrated for several members of the TGF $\beta$ superfamily in early Xenopus embryos (Green and Smith 1990; Dosch et al. 1997; Wilson et al. 1997) and for the bone morphogenetic protein (BMP) homolog decapentaplegic (dpp) in the early Drosophila embryo and wing disc (Gelbart 1989; Ferguson and Anderson 1992; Wharton et al. 1993; Lecuit et al. 1996; N ellen et al. 1996). The intracellular mechanisms by which ligand dose can be transduced into multiple developmental fates is therefore a current focus of interest for understanding TGF $\beta$ S as morphogens.

A second striking feature of TGF $\beta$ superfamily signals is the variety of effects they can evoke, contingent on the developmental history of the responding cell. For example, at the gastrula stage, BM P2 can specify frog blastomeres as epidermal rather than neural progenitors (Wilson et al. 1997); at later stages it can specify dorsoventral pattern in the neural tube (for review, seeT anabe and Jessell 1997), neural crest (NC) cells to form neuronal rather than Schwann cells (for review, see M ehler et al. 1997), and apoptotic patterning of the NC during rhombomere segmentation (Graham and Lumsden 1996). How the developmental history of a particular cell intersects with an instructive signal from a TGF $\beta$ super-

1E-MAIL mwhitman@warren.med.harvard.edu; FAX (617) 432-1144. family ligand to generate a cell type-specific developmental decision is therefore a second critical question in understanding how these ligands function in developmental patterning. A third central issue, closely tied to the first two, is how other signaling pathways that participate in devel opmental patterning interact with TGF $\beta$ superfamily signal s. Over the past 10 years considerable progress has been made in understanding where and when different TGF $\beta$ superfamily ligands signal in embryos and defining characteristic transcriptional responses that mark their effects. Understanding the molecular basis for patterning, however, will al so require a knowledge of how the intracellular signal transduction of TGF $\beta$ s integrates ligand dose, devel opmental history, and signals from other pathways to generate the complex set of responses observed during embryogenesis.

Until recently, very little has been known about how TGF $\beta$ superfami ly signals are transduced intracellularly. This situation has changed rapi dly over the past 3 years, however, with the discovery and characterization of the Smad family of gene products as transducers of TGF $\beta$ superfamily signals (for review, see Derynck and Feng 1997; Heldin et al. 1997; Attisano and Wrana 1998; M assagué 1998). Although our understanding of how Smads mediate cell type-specific transcriptional regulation is still incomplete, characterization of these signal transducers has begun to provide a molecular framework within which to investigate in detail how the TGF $\beta$ superfamily of factors regulates complex patterns of cell specification. In addition to providing our first picture of how TGF $\beta$ signals directly regulate transcription, studies of Smad regulation have begun to provide clues as to how cells integrate multiple signals from both TGF $\beta$ and non-TGF $\beta$ signaling pathways. Recent work on the extracellular regulation of BM Ps during embryogenesis has provided a dramatic advance in the understanding of BMP-dependent patterning mechanisms conserved between vertebrates and invertebrates (Holley et al. 1995; Piccolo et al. 1996; Zimmerman et al. 1996); recent advances in understanding intracellular regulation by TGFßs provides new opportunities for examining their function in patterning at multiple steps in embryogenesis.

TGF $\beta$ superfamily signal transduction has been the subject of numerous reviews over the past 2 years (see above). This review will provide a relatively cursory 
summary of the work reviewed previously to concentrate on more recent work on Smads as a focal point for thinking about possible mechanisms both for TGF $\beta$ signaling specificity and for integration of multiple signaling pathways during embryogenesis.

\section{Transduction background: the receptors}

The first step in signaling by TGF $\beta$ superfamily factors is the binding of ligand to transmembrane receptors. In general, TGF $\beta$ superfamily ligands bind and thus bring together two distinct types of receptors, designated type I and type II (see Derynck and Feng 1997; Massagué 1998). Both receptor types are serine-threonine-specific protein kinases; upon ligand binding, the type II receptor phosphorylates the type I receptor, which is activated and, in turn, is responsible for intracellular signaling. Although type I and type II receptors have been named according to the ligands they can bind, the full set of physiologically significant combinations of ligands and type I/II receptors that interact in vivo has not been fully described (Derynck and Feng 1997). Some ligands (e.g., TGF $\beta$ and possi bly activin) al so have a non-serine-threonine kinase type III receptor that facilitates or modulates binding to type I/II receptors (Lopez-Casillas et al . 1993), and different I/II pairs may vary significantly in the relative contributions of the type I and type II receptors to the affinity and specificity of ligand binding (for review, see Derynck and Feng 1997; M assagué 1998). Because the type I receptors appear to be the primary determinants of intracellular signaling specificity (Carcamo et al. 1994), the range of cellular responses a given ligand can elicit may depend significantly on exactly which combinations of type I/II receptors can bind ligand in a given target cell.

\section{The discovery of Smads in D rosophila and $C$ aenorhabditis elegans}

The characterization of type I receptors as signal transducing serine-threonine-specific protein kinases immediately raised the question of what are the downstream targets for these kinases. A potential answer came from a Drosophila genetic screen for maternal effect mutations that enhance the phenotype of weak alleles of dpp, a Drosophila BMP homolog (Raftery et al. 1995). Multiple enhancing mutations were found in a gene named Mothers against dpp (Mad) (Raftery et al . 1995; Sekel sky et al. 1995). Genetic and sequencing analysis showed that Mad encodes a novel protein that acts cell autonomously downstream of $D p p$ and the $D$ pp type I receptor thick veins (Tkv) (Sekelsky et al. 1995; Hoodless et al. 1996; N ewfeld et al . 1996; Wiersdorff et al. 1996). A second gene from the same screen, Medea, has subsequently been shown to share significant homology with Mad and to also act downstream of Dpp (Das et al. 1998; Hudson et al. 1998; Wisotzkey et al. 1998). In the nematode Caenorhabditis elegans, cloning and sequencing of several genes implicated in a pathway regulated by a TGF $\beta$ receptor homolog (daf-4) (Estevez et al. 1993) identified a family of genes (sma-2, sma-3, and sma-4) with clear homology to Mad, suggesting that the Mad/sma genes might represent a broadly conserved family encoding proteins involved in TGF $\beta$ superfamily signaling (Savage et al. 1996). Because of the dual origin of this family of genes, and the pre-existence of unrelated proteins abbreviated as MAD, the family defined by the homology between MAD and sma-2,3,4 was renamed Smad (Derynck et al. 1996).

\section{The vertebrate Smads}

Following closely on the heels of the identification of Drosophila and nematode Smads, vertebrate Smad homologs were identified in EST database searches, by degenerate oligonucleotide PCR and by independent functional expression screens in Xenopus. A total of nine vertebrate Smads have been identified (a number that is still rapidly changing), as well as two in Drosophila, and five in nematodes. M ost of the invertebrate Smads have been identified as homologs of specific vertebrate Smads on the basis of both primary sequence and functional criteria; for example, $\mathrm{M}$ ad is functionally similar to Smad1 (N ewfeld et al. 1996) and Medea and Sma-4 are similar to Smad4 (Savage et al. 1996; Das et al. 1998; Wisotzkey et al. 1998). However, some invertebrate Smads (e.g., daf-3) (Patterson et al. 1997) have no clear homolog yet identified in vertebrates.

An indication that Smads might be able to mimic TGF $\beta$ superfamily signals came from overexpression studies in Xenopus. Expression of either full-length Smad2 or its carboxy-terminal half mimics the mesoderm-inducing effects of activin on animal pole blastomeres (Baker and Harland 1996; Graff et al. 1996). Overexpression of Smad1 or Smad5, in contrast, mimics the ventralizing effects of BMP4 (Liu et al. 1996; Thomsen 1996; Suzuki et al. 1997a). These observations not only demonstrated that Smads can mimic TGF $\beta$ superfamily signals but also suggested that different Smads might transduce distinct TGF $\beta$ superfamily signals. Concomitant observations that BMP4 stimulates Smad1 phosphorylation and translocation to the nucleus (Hoodless et al. 1996; Liu et al. 1996), whereas activin or TGF $\beta$ stimulates Smad2 phosphorylation and nuclear translocation (Baker and Harland 1996; Eppert et al. 1996; Yingling et al. 1996), confirmed that these Smads participate in distinct TGF $\beta$ superfamily signaling pathways. Identification and characterization of additional Smads has led to the designation of three distinct categories of Smads: (1) those that are di rectly phosphorylated by type I receptors and when overexpressed mimic specific signaling pathways ("pathway-specific" or "receptor-regulated" Smads, e.g., vertebrate Smad1, Smad2, Smad3, Smad5, and Smad8, Drosophila M ad); (2) those that appear to be shared among multiple signaling pathways (e.g., vertebrate Smad4 and Drosophila Medea); and (3) those that when overexpressed inhibit TGF $\beta$ superfamily signaling [“inhibitory Smads," e.g., vertebrate Smad6, Smad7, and Drosophila Daughters against Dpp (Dad)]. There remain some Smads that have not been catego- 
rized definitively in this framework (e.g., daf-3), and as there are still many more TGF $\beta$ superfamily ligands than there are receptor-regulated Smads, it seems likely that many ligands, and possibly some type I receptors, may share common receptor-regulated Smads for their signaling. Although the three categories listed above provide a general framework for how Smads work, the definition and number of these categories may change as our understanding of Smads progresses. T able 1 provides a summary of some of the best understood sets of components of TGF $\beta$ superfamily signaling pathways.

\section{Domain structure of Smads}

Examination of the primary sequence of Smads revealed extensive sequence homology among Smads in two distinct regions: an amino-terminal domain designated the $\mathrm{N}$ or Mad homology 1 ( $\mathrm{MH} 1$ ) domain, and a carboxyterminal domain designated the $\mathrm{C}$ or $\mathrm{MH} 2$ domain. All Smads identified to date contain a recognizable $\mathrm{M} \mathrm{H} 2$ domain; however, the inhibitory Smads have poorly conserved $\mathrm{MH} 1$ domains. The region between the $\mathrm{MH} 1$ and $\mathrm{MH} 2$ domains is referred to as the linker region and is poorly conserved among Smads. Functional analysis of Smad point and deletion mutations (Baker and Harland 1996; Hata et al. 1997) suggests that in the inactive state, the $\mathrm{MH} 1$ and $\mathrm{MH} 2$ domains associate with one another. Receptor activation then opens up this structure to activate the effector functions of each domain (discussed below).

\section{Smad heterodimerization-the necessity of Smad4}

Genetic analysis of the C. elegans Smads (sma-1,2,3) indicated that multiple Smads are required in the same tissue to transmit upstream signals (Savage et al. 1996). A specific mechanism for this cooperation was provided

Table 1. Molecular components of TGF $\beta$ superfamily signal transduction

\begin{tabular}{|c|c|c|c|c|c|c|c|c|}
\hline \multirow[b]{2}{*}{ Ligands } & & \multicolumn{3}{|c|}{ Receptor } & \multirow{2}{*}{\multicolumn{2}{|c|}{$\begin{array}{l}\text { Receptor- } \\
\text { regulated } \\
\text { Smad }\end{array}$}} & \multirow{2}{*}{\multicolumn{2}{|c|}{$\begin{array}{c}\text { Common } \\
\text { Smad }\end{array}$}} \\
\hline & & type II & & type I & & & & \\
\hline Activin & $\rightarrow$ & $\begin{array}{c}\text { ActRII } \\
\text { ActRIIB }\end{array}$ & $\rightarrow$ & ActRIB & $\rightarrow$ & $\begin{array}{l}\text { Smad2 } \\
\text { Smad3 }\end{array}$ & $\rightarrow$ & Smad4 \\
\hline TGF $\beta$ & $\rightarrow$ & $\mathrm{T} \beta \mathrm{RII}$ & $\rightarrow$ & $\mathrm{T} \beta \mathrm{RI}$ & $\rightarrow$ & $\begin{array}{l}\text { Smad2 } \\
\text { Smad3 }\end{array}$ & $\rightarrow$ & Smad4 \\
\hline $\mathrm{BM} \mathrm{P} 2 / 4$ & $\rightarrow$ & $\begin{array}{c}\text { BM PRII } \\
\text { ActRII }\end{array}$ & $\rightarrow$ & $\begin{array}{c}\text { BMPRI } \\
\text { BM PRIB }\end{array}$ & $\rightarrow$ & $\begin{array}{l}\text { Smad1 } \\
\text { Smad5 } \\
\text { Smad8 }\end{array}$ & $\rightarrow$ & Smad4 \\
\hline Dpp & $\rightarrow$ & Punt & $\rightarrow$ & $\begin{array}{l}\text { Tkv } \\
\text { Sax }\end{array}$ & $\rightarrow$ & MAD & $\rightarrow$ & M edea \\
\hline
\end{tabular}

Listed are examples of components of relatively well-characterized TGF $\beta$ superfamily transduction pathways discussed in this review. The list is not intended to be comprehensive either with respect to ligands in the superfamily or transducers that may potentially act downstream of a ligand shown. More comprehensive discussions of TGF $\beta$ superfamily ligands and their receptors may be found in Derynck and Feng (1997) and M assagué (1998). by biochemical analysis of the vertebrate Smads: The pathway-specific Smads heterodimerize with Smad4 in response to ligand stimulation (Lagna et al. 1996; Zhang et al. 1996, 1997). This heterodimerization appears to be necessary for signaling, as cell lines that lack Smad4 do not respond to TGF $\beta$ signals, and signaling can be restored by transfection of wild-type Smad4 (Lagna et al. 1996; de Caestecker et al. 1997). Recent genetic data from Drosophila reveal a requirement for the Smad4 homolog M edea in D pp/M ad signaling, indicating that this heterodimerization mechanism is conserved between vertebrates and invertebrates (Das et al. 1998; Hudson et al. 1998; Wisotzkey et al. 1998). Crystallization of the $\mathrm{MH} 2$ domain of Smad4 revealed that it forms a trimer (Shi et al. 1997), and conservation of primary amino acid sequence at the crystal trimer interfaces suggests that all the Smads may have the capacity to trimerize. In the case of Smad2 and Smad3, which have highly homologous $\mathrm{MH} 2$ domains and interact with one another in a TGF $\beta$-regulated manner ( $\mathrm{N}$ akao et al. 1997b), receptorregulated trimerization may also occur. In light of the extensive primary sequence homology between $\mathrm{M} \mathrm{H} 2$ domains of different Smads, whether the Smad4-M H2 homotrimers observed in vitro reflect a propensity solely for homotrimerization in vivo, or whether heterotrimerization may be mediated by homologous interfaces in other Smads, is not understood. Mutations that disrupt trimerization disrupt Smad4 function, indicating that trimeric $\mathrm{M} \mathrm{H} 2-\mathrm{M} \mathrm{H} 2$ interactions are functionally important (Shi et al. 1997), but to what extent Smad trimerization occurs among full-length Smads in vivo, whether this trimerization is constitutive or regulated, and to what extent it is homotrimerization or heterotrimerization all remain to be established.

\section{Activation of Smads}

Smad1, Smad2, and Smad3 and, by inference, Smad5 and Smad8, are directly phosphorylated at their carboxyl termini by type I TGF $\beta$ superfamily receptors (M acias-Silva et al. 1996; Zhang et al. 1996; Kretzschmar et al. 1997b) and therefore are often referred to as receptor-regulated Smads. Smad4 lacks this carboxy-terminal phosphorylation sequence and does not appear to be a substrate for the type I receptors. The specificity of this phosphorylation by upstream receptors generally consistent with the observed downstream effects of ectopic Smad activation-that is, Smad1, which when overexpressed mimics BM P signaling, is phosphorylated by the type I BM P receptor (Kretzschmar et al. 1997b), and Smad2, which mimics the effects of activin, is phosphorylated by the ActRIB or T $\beta R 1$ receptors (Macias-Silva et al. 1996). Phosphorylation occurs at two serines in a SSXS motif conserved among the pathway-specific Smads (Abdollah et al. 1997; Souchelnytski et al. 1997), and TBR1 the specificity of receptor interaction-phosphorylation is determined by a conserved 17-amino-acid region in the MH2 domain referred to as the L3 loop (Lo et al. 1998). Phosphorylation is mediated by direct association be tween the Smad and the type I receptor, occurs within 
minutes of receptor stimulation, and is requi red both for signaling and association of receptor-regulated Smads with Smad4 (Macias-Silva et al. 1996; Kretzschmar et al . 1997b).

U pon ligand stimulation, Smads translocate from the cytosol to the nucleus, and this translocation also appears to be regulated by phosphorylation at the carboxyl terminus (Liu et al. 1996). Ligand-stimulated nuclear translocation of the receptor-regulated Smads does not appear to requi re association with Smad4 (Li u et al . 1997; Wisotzkey et al. 1998). Smad4, in contrast, does require a phosphorylated pathway-specific Smad to accumulate in the nucleus, indicating that heterodimerization with receptor-regulated Smads drives Smad4 nuclear accumuIation (Liu et al. 1997; Wisotzkey et al. 1998). Isolated $\mathrm{MH} 2$ domains of receptor-regulated Smads accumulate in the nucleus constitutively (Baker and Harland 1996), suggesting that the $\mathrm{MH} 1 /$ linker domains may either occlude sequences in the $\mathrm{MH} 2$ domain that are responsi ble for nuclear localization or contain a sequence that directs cytoplasmic retention of the protein in the absence of carboxy-terminal phosphorylation. Smads do not contain a recognizable nucl ear localization signal, and so the mechanism by which they accumulate in the nucleus remains unknown.

\section{How Smads signal}

The phosphorylation of pathway-specific Smads by type I TGF $\beta$ superfamily receptors and their subsequent heterodimerization with Smad4 and translocation to the nucleus form the basis for a simple model for how Smads transduce signals from the plasma membrane to the nucleus (Fig. 1). The next question is: What do Smads do there? Three types of activities have been demonstrated for Smads that point to mechanisms by which they might di rect specific transcriptional responses: (1) a transcriptional transactivation function intrinsic to the $\mathrm{M} \mathrm{H} 2$ domain; (2) specific association with a nucl ear transcription factor; or (3) DNA-binding activity intrinsic to the $\mathrm{MH} 1$ domain.

\section{The $\mathrm{MH} 2$ domain is a transcriptional activator}

Intrinsic transcriptional transactivation activity has been demonstrated for $\mathrm{MH} 2$ domains of both receptorregulated Smads and Smad4 by fusion of the $\mathrm{MH} 2$ domain to a Gal4 DNA-binding domain (Liu et al. 1996). Full-length Smad4 fused to the Gal4 DNA-binding domain lacks this activity, and full-length Smad1 fused to Gal4 requires activation by BM $P$ receptor for activity, supporting the idea that the $\mathrm{MHI}$ domain may negatively regulate the activity of the $\mathrm{MH} 2$ domain. In addition, transcriptional activation by Gal4-Smad1 or Gal4Smad2 in vertebrate cells requires the coexpression of Smad4 or, at a minimum, expression of the Smad4 M H2 domain (Liu et al. 1997). Heterodimerization of the receptor-regulated Smads with Smad4 may therefore be essential for the localization of the transcriptional activation function of the Smad4 M H2 domain to the nucleus.

\section{Smad association with a nuclear transcription factor}

A mechanism for targeting the Smad transcriptional activation function to specific responsive promoters has been provided by the demonstration of a regulated association between Smads and a nuclear transcription factor, FAST-1, in early frog embryos (Chen et al. 1996, 1997; Liu et al. 1997). In this system, stimulation of cells with activin leads to the association of Smad2 and Smad4 with FAST-1, a winged helix transcription factor. This complex can bind to a regulatory element, the ac-
Figure 1. A general scheme of Smads as TGF $\beta$ superfamily signal transducers. (See text for a discussion).

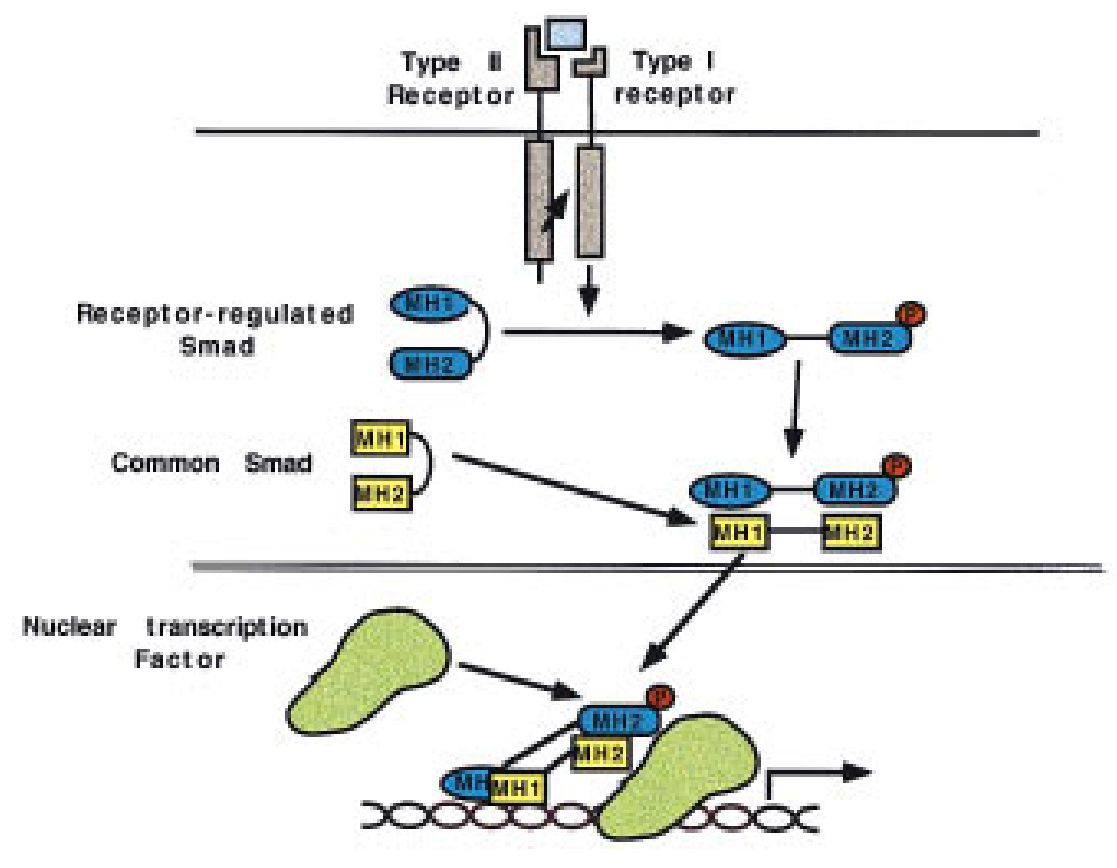


tivin responsive element (ARE) in the promoter of an activin-responsive gene, Mix.2 (Huang et al. 1995). The interaction between Smad2 and FAST-1 is direct and is mediated through the $\mathrm{MH} 2$ domain of Smad2 and a domain near the carboxyl terminus of FAST - 1 termed the Smad interaction domain (SID; Chen et al. 1997). Association of Smad4 with FAST -1 requires sequences in the SID in addition to those required for Smad2 binding, but at this point there is no evidence for a direct interaction between Smad4 and FAST-1. Ectopic expression of FAST - 1 is not sufficient to activate the ARE but is required for activin or TGF $\beta$ stimulation of the ARE in tissue culture cells (Hayashi et al. 1997; Liu et al. 1997), indicating that FAST-1 is necessary for the targeting of the Smad2/Smad4 complex to this activin/TGF $\beta$ responsive promoter element. An activin-regulated complex among Smad2, Smad4, and an as yet unidentified transcription factor has also been identified in frog embryos as binding to an element (unrelated to the Mix.2 $A R E$ ) in the promoter of the activin early response gene goosecoid, indicating that there are probably multiple transcription factors mediating Smad2/Smad4 induction of mesodermal responses in early embryos (Candia et al. 1997).

\section{Smad $\mathrm{MHI}$ domains bind DNA}

In addition to targeting promoters via transcription factors like FAST-1, Smads have an intrinsic, site-specific DNA-binding activity. This activity was first demonstrated for the $\mathrm{MH} 1$ domain of $\mathrm{M}$ ad, which binds a site in a Dpp-responsive el ement the gene vestigial (vg) in vitro (Kim et al . 1997); The isol ated MHI domain binds more potently than the full-length protein, suggesting that the $\mathrm{MH}$ 2/linker regi ons may negatively regulate DN A-binding activity. Mad (or Medea) binding sites have been identified in several other Dpp responsive elements: a $\mathrm{Dpp}$ responsive enhancer in the mesoderm-response gene tinman is bound and synergistically activated by Medea and Tinman itself ( $X u$ et al. 1998); on the other hand a $\mathrm{M}$ ad binding site in the minimal Dpp-responsive promoter for the ultrabithorax ( $\mathrm{U}$ bx) gene is not required for Dpp regulation in vivo (Kim et al. 1997), suggesting that DNA binding by Mad may not in all cases be necessary for Mad-mediated transcriptional regulation.

DNA-binding activities have also been demonstrated for vertebrate Smad3 and Smad4: An optimal target site for Smad3 or Smad4 has been defined both by examination of promoter sites and by oligonucleotide sel ection as containing a core GTCT (or its palindrome CAGA) (Dennler et al. 1998; Zawel et al. 1998); binding sites identified in promoters seem to vary significantly around this core. A concatamer of consensus Smad binding sites is sufficient to confer TGF $\beta$ responsiveness on a reporter, indicating that direct Smad binding to DN A can be sufficient for transcriptional regulation by TGF $\beta$ (Dennler et al. 1998; Zawel et al. 1998). In addition to binding to artificial consensus sites, Smad3 or Smad4 al so binds to TGF $\beta$-regulated elements derived from the collagenase and PAI-1 promoters. In the case of the collagenase pro- moter, binding to a 31-bp sequence that contains an AP-1 site and confers TGF $\beta$ responsiveness has been shown (Yingling et al . 1997). In contrast to the case of the Drosophila vg enhancer, however, elimination of the Smad3/Smad4 binding site from this 31-bp enhancer does not eliminate TGF $\beta$ or Smad4 overexpression-mediated induction of an enhancer-reporter construct. The adjacent AP-1 site is necessary for TGF $\beta$ - and Smad4mediated activation, suggesting that AP-1 may be a component of Smad activation in this system (Yingling et al. 1997). In the PAI-1 promoter, three separate Smad3/ Smad4 binding sites have been identified; elimination of all three, but not any two, eliminates TGF $\beta$ responsiveness of the promoter (Dennler et al. 1998). In the case of the Xenopus ARE, Smad4 also binds the DN A element di rectly, at a site distinct from the binding site for FAST1. Mutation of the FAST-1 binding site eliminates responsiveness of the element, whereas mutation of the Smad4 binding site reduces, but does not eliminate, activin responsiveness (C.Y. Yeo, X. Chen, and $M$. Whitman, unpubl.).

\section{Models for transcriptional regulation by Smads}

Observations from Xenopus and D rosophila embryos, as well as vertebrate tissue culture cells, suggest several possi ble modes by which Smads regulate responsive promoter/enhancers (Fig. 2). First, they may form stable protein-protein complexes with other transcription factors, such as FAST-1; DNA recognition by this complex then results from the combined DN A-binding affinities of the Smads and the additional transcription factor (Fig. 2A). Second, Smads and other transcription factors may bind at nearby promoter/enhancer target sites, with proteinprotein interactions providing cooperativity to the binding and thereby enhancing the specificity or affinity of promoter/enhancer recognition (Fig. 2B). Third, Smads and other regulatory factors may bind independently but synergistically regulate transcription (Fig. 2C), as has been suggested for regulation of tinman in the Drosophila mesoderm (Xu et al. 1998). Clearly these different modes may fall on a continuum rather than representing discrete al ternatives, and the relative contributions of Smad and auxiliary transcription factor binding to specific DN A binding may vary substantially between specific promoters. Whereas the details of how the different Smad functions are applied in inidvidual cases remain to be worked out, the intrinsic transcriptional activation function of Smads, their ability to interact specifically with other transcription factors, and their ability to directly target promoter/enhancer regulatory sites provide a general framework for investigating their roles in the regulation of gene expression.

\section{Smad expression pattems in embryos}

Expression of the signaling Smads appears to be widespread during embryogenesis. mRN As encoding Smad1, Smad2, and Smad4 are present maternally and expressed ubiquitously in early frog embryos (Graff et al. 1996; Lagna et al. 1996), and in D rosophila early embryos, Mad 
Figure 2. Three mechanisms for Smad/ transcription factor coregulation of promoter/enhancer elements. Shown is a schematic of three variations on coregulation of transcription at enhancer elements by Smads and other DNA-binding proteins. (A) Ligand-regulated protein-protein interactions drive association of Smads with other DNA-binding proteins to form a multiprotein complex that coordinately binds multiple target sites within an enhancer; (B) Smads and additional factors recognize target sites separately, but protein-protein interactions stabilize binding-to-target-site region, en-hancing affinity/specificity; (C) Smads and additional factors bind target sites independently but act additively or synergistically in the activation of transcription.

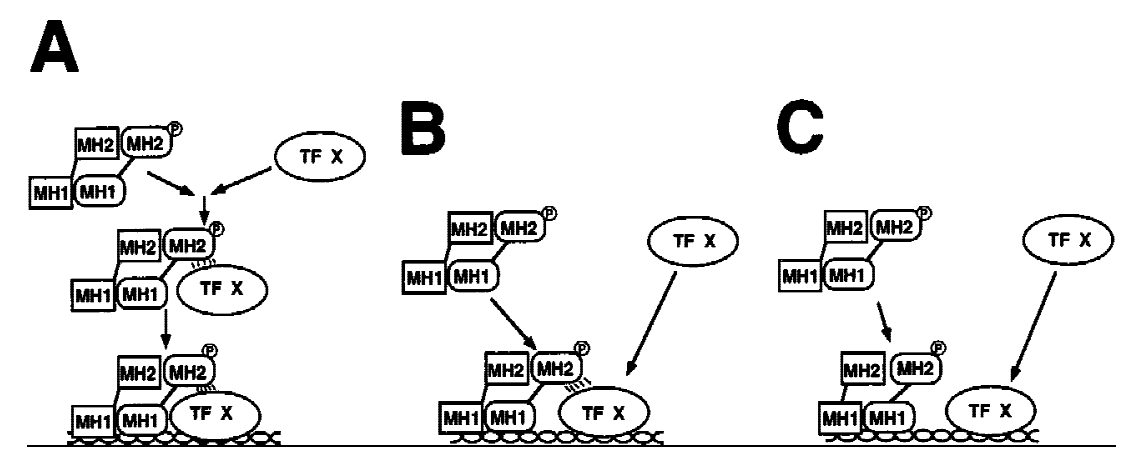

and Medea RNAs are al so expressed ubiquitously (N ewfel d et al . 1996, 1997; Das et al. 1998; Hudson et al. 1998; Wisotzkey et al. 1998). In mice, Smad1 is expressed first in the early embryonic mesoderm, and later ubiquitously, whereas Smad2 and Smad4 are ubiquitous (in both embryonic and extraembryonic tissues) through day 8.5 of embryogenesis (Wal drip et al. 1998; Y ang et al . 1998). During organogenesis in the mouse, increased Smad1 and Smad2 expression is seen in a variety of developing organs at sites of epithelial-mesenchymal interactions (Dick et al. 1998). Although expression patterns for several signaling Smads (e.g., Smads 3, 5, and 8) have not been reported, the broad spatial and temporal expression of signaling Smads examined so far would seem to indicate that in general, differential expression of these Smads is not a critical determinant of cell typespecific responses to TGF $\beta$ superfamily signals. The possibility remains that additional tissue or cell type-specific signaling Smads may be identified, as well as that tissue-specific enrichment of Smad expression is important in the development of distinct responses to TGF $\beta$ superfamily signaling. In early development, however, cell type-specific responses to TGF $\beta$ superfamily signals seem at this point likely to involve differential expression of mediators downstream of Smads (e.g., tissue or developmental stage-restricted transcription factors like FAST-1 or Tinman) rather than differential expression of the signaling Smads themselves.

\section{Smad functions in embryos: loss of function in D rosophila}

Three general types of experiments have provided our current picture of patterning steps regulated by Smads during early embryogenesi s: (1) genetic loss-of-function experiments in Drosophila; (2) ectopic expressi on experiments in Xenopus; and (3) genetic loss of function in mice by homol ogous recombination. In Drosophila, Dpp is required for multiple steps in embryogenesis, oogenesis, dorsoventral patterning of the embryonic ectoderm, midgut, and adult appendages and eyes (for review, see
Gelbart 1989; Kingsley 1994). In both the wing imaginal disc and the embryonic ectoderm, Dpp appears to act as a morphogen, regulating embryonic pattern in a concentration-dependent manner (Ferguson and A nderson 1992; Wharton et al. 1993; Lecuit et al. 1996; Nellen et al. 1996). mad was originally identified as a genetic modifier of dpp (Raftery et al. 1995; Sekelsky et al. 1995); subsequent analysis has demonstrated that for each of the developmental events requiring patterning by Dpp signal s, loss of $\mathrm{M}$ ad function results in a phenotype similar to loss of Dpp (Sekelsky et al. 1995; Newfeld et al. 1996; Wiersdorff et al. 1996). M ad is closest in sequence to Smad1, consistent with its role as a receptor-regulated Smad acting downstream of a BMP homolog. Medea is also necessary for dorsal-ventral patterning by $D p p$, and loss of Medea cannot be compensated for by increase levels of M ad (Das et al. 1998; Wisotzkey et al . 1998), as might be expected from the Smad heterodimerization model developed in vertebrates. Decreased M edea function suppresses the phenotype associated with activation of the dpp type I receptor Sax, al so consistent with the proposed vertebrate pathway (Das et al. 1998).

Although in general Medea appears to be necessary for Mad/D pp signaling, detailed characterization of Medea loss-of-function alleles reveals several complications. Whereas decreased Medea function suppressed the effects of activated Sax, it did not suppress the phenotype associated with activation of Tkv, another type I D pp receptor (Das et al. 1998). The differences in Medea requirements for Sax and Tkv may reflect simply distinct dosage sensitivities of the receptors to $M$ edea level s but might also suggest the use of M edea-independent signaling mechanisms by the Tkv receptor. An additional puzzle arises from examination of mutant Medea clones in the developing wing disc: Mutant Medea clones that develop close to the source of Dpp at the anterior-posterior compartment boundary express a Dpp and Maddependent gene (omb) normally, whereas mutant Medea clones more distant from the Dpp source fail to express omb normally (Wisotzkey et al. 1998). Although the developmental characterization of Medea indicates that it 
is generally required for $\mathrm{Dpp}$ signaling, this requirement may not be the same for all Dpp-responsive genes. The possible existence of a Smad4-like gene in Drosophila in addition to Medea has not been excluded, but these observations raise the possibility that Smad heterodimerization may not be as universally obligatory as the vertebrate data have implied.

Dpp is differential ly expressed across the tissues it patterns (Wharton et al. 1993; N ellen et al. 1996), whereas $\mathrm{M}$ ad and $\mathrm{M}$ edea are expressed ubiquitously. Because the I oss of $M$ ad or Medea function results (with the exceptions noted above) in defects consistent with the absence of a Dpp signal, this would suggest a simple model (e.g., in the case of dorsal-ventral patterning of the early ectoderm) in which a Mad/M edea complex is activated in proportion to a graded Dpp signal, and this intracellular gradient of $M$ ad/M edea activity specifies tissue-specific transcription patterns. That $M$ ad can bind directly to response elements in D pp-responsive promoters raises the possibility that Dpp patterned transcription is a direct readout from graded $\mathrm{M}$ ad or $\mathrm{Mad} / \mathrm{M}$ edea promoter/enhancer binding. Similar gradients of Mad-M edea function may be used for tissue patterning at multiple stages in Drosophila (e.g., dorsoventral patterning of early ectoderm, anterior-posterior patterning of wing imaginal disc; morphogenesis of visceral mesoderm). The different $\mathrm{Dpp} / \mathrm{Mad} / \mathrm{M}$ edea transcriptional responses characteristic for each stage and tissue would then presumably be dictated by the presence of stage- or tissue-specific transcriptional activators or repressors that either help to target $\mathrm{M}$ ad/M edea to specific promoters/enhancers or bind independently of $\mathrm{Mad} / \mathrm{M}$ edea and synergize with (or antagonize) $\mathrm{Mad} / \mathrm{Medea}$ transcriptional regulation (Xu et al. 1998).

The genetic loss-of-function experiments in Drosophila strongly indicate that $\mathrm{M}$ ad and, in most cases, Medea, are necessary for Dpp-dependent patterning. If they are in fact the principal intracellular transducers defining patterned responses to $\mathrm{dpp}$, it should also be possible to show that (1) they are activated in a gradient corresponding to the gradient of Dpp activity, and (2) that ectopic generation of Mad/M edea activity is sufficient to specify pattern as does Dpp. The demonstration that Dpp overexpression can cause nuclear accumulation of Mad in vivo (N ewfeld et al . 1997) makes feasible the immunocytochemical examination of whether there is in fact differential or graded $M$ ad activation in tissues in which patterning by $\mathrm{Dpp}$ is taking place. This has been examined in blastoderm embryos and wing discs; contrary to what might have been expected from the differential expression and activity of Dpp across the blastoderm, uniform cytoplasmic concentration of $\mathrm{Mad}$ was observed (N ewfeld et al. 1997). The meaning of this negative result is not certai $n$, but the interpretation most easily reconciled with other data would seem to be that in the blastoderm Mad protein is present in substantial excess over what is needed for endogenous signal ing. In this case the quantity of $\mathrm{M}$ ad that is translocated to the nucleus in response to endogenous signals is too little to detect against the background of excess $M$ ad, whereas an ectopic, high-level Dpp signal may be sufficient to cause net nuclear accumulation of even the excess Mad. Examination of the spatial and temporal distribution of $\mathrm{Mad}$ activation remains an important test of its role in patterning, but additional tools (e.g., activation-specific M ad antibodies) may be necessary to test the prediction that $M$ ad is differentially activated in Dpp-patterned tissues.

The second question, of whether direct activation of Mad can effectively mimic Dpp patterning signals should, if experiments with Smads in vertebrates are an appropriate guide, be possible to do by overexpression of wild-type or amino terminally truncated Mad. Ectopic expression of wild-type $\mathrm{M}$ ad and Medea in Drosophila does not, however, seem to be sufficient to perturb embryonic patterning (Hudson et al. 1998). Whether this is due to technical limitations (i.e., ectopic Smad protein expression in Drosophila is much less than can be achieved in Xenopus) or to more stringent post-translational regulation of Drosophila $\mathrm{M}$ ad/ $\mathrm{M}$ edea than of vertebrate Smads is not clear. In any case, data from ectopic expression of Smads in Xenopus embryos have largely complemented the Drosophila loss-of-function experiments to address how activation of Smads can mimic endogenous patterning signals during development.

\section{Ectopic expression in Xenopus}

\section{TGF $\beta$ ligands may be morphogens}

As in Drosophila, there is substantial evidence that TGF $\beta$ superfamily ligands have a major role in patterning the early vertebrate embryo and that they may function as morphogens, specifying multipl e tissue types as a response to graded concentrations of ligand. M ost of this evidence has come from studies in Xenopus, in which it is relatively straightforward to apply (by mRNA injection into embryos or factor addition to isolated tissue) graded doses of ligands and assess their effects on developmental fate (Smith 1987; Green et al . 1992; Gurdon et al. 1994). Ectopic activin and BM P4 each induce a range of tissue types when added to early ectodermal cells, with activin inducing lateral mesoderm at low doses and more dorsal mesoderm at high doses (Green et al. 1992). BMP4 can induce dissociated ectodermal cells to form cement gl and at low doses and epidermis at higher doses, and at still higher doses ventral mesoderm can also be induced (Dale et al. 1992; Jones et al. 1992). In the absence of BM $P$ these cells form neural tissue (Wil son et al. 1997). In addition to these effects on isol ated prospective ectoderm, BMP4 ventralizes the body axis when expressed in intact embryos-that is, expands the expression of ventral mesodermal tissues at the expense of dorsal mesodermal and neural tissues and structures (Jones et al. 1992; Dosch et al. 1997). Conversely, inhibition of BM $P$ by addition of the antagonist Noggin can progressively induce cement gland at low doses and cpl-1, a dorsal forebrain marker, at higher doses (Knecht and Harland 1997), suggesting that gradients of inhibitors of signal-generating ligands may also help to establish early pattern. Inhibition of BM P signaling by ectopic expression of a dominant inhibitory BM $\mathrm{P}$ receptor dorsalizes 
ventral mesoderm (Graff et al. 1994; Suzuki et al. 1994), and expression of a dominant-inhibitory activin receptor that inhibits TGF $\beta$ superfamily signaling in general (Schulte-M erker et al. 1994) can prevent the formation of mesoderm entirely (Hemmati-Brivanlou and M elton 1992). Although dominant-inhibitory receptors are not sufficiently specific tools to distinguish the role of individual ligands, these observations generally support a role for BM $\mathrm{P}$ and activin-like ligands in endogenous patterning.

Although the ectopic expression of TGF $\beta$ superfamily ligands and of Smads in embryos is consistent with multiple morphogenic roles for these signals, the actual distribution of these signals in vivo is not clear (for review, see Conlon et al. 1996; Harland and Gerhart 1997). For the Smad2 signaling pathway, the identity of the upstream ligand or ligands most important for early patterning remains obscure. In Xenopus, activin, $\mathrm{Vg}-1$, and several of the nodal-rel ated genes may all lead to Smad 2 activation (Baker and Harland 1996; Chen et al. 1996; Graff et al. 1996; Nomura and Li 1998), and RNAs encoding these factors are present at embryonic stages consistent with at least some role in mesodermal induction and patterning (Weeks and Melton 1987; Jones et al. 1992; Dohrmann et al. 1993; Thomsen and M elton 1993; Oda et al. 1995; Lustig et al. 1996). It has not been possible to determine where and when the corresponding ligands may be secreted and active during development, leaving open the question of which ligands are responsible for Smad2 activation in vivo, as well as the temporal and spatial patterns of this activation.

In the case of BM Ps, RN As encoding BM P2, BM P4, and BMP7 are present maternally (Nishimatsu et al. 1992, 1993); BMP2 and BMP4 have been shown to be present throughout the ventral embryonic ectoderm and mesoderm in which they are proposed to act ( $\mathrm{N}$ ishimatsu et al. 1993; Hemmati-Brivanlou and Thomsen 1995; Schmidt et al. 1995b). All three seem to have similar activities (Suzuki et al. 1997b), are thought to signal through Smad1, and may heterodimerize to act synergistically. Dorsalizing/neuralizing factors that antagonize the BM Ps are expressed in the organizer (Re'em-Kalma et al. 1995; Piccolo et al. 1996; Zimmerman et al. 1996), leading to the proposal that a gradient of BMP signaling is established initially by the interaction of broadly expressed BMPs with a dorsally localized source of BMP antagonists. Consistent with this, the order in which different ectodermal derivatives are induced by increasing concentrations of BM Ps corresponds roughly to their distance on the fate map of a gastrula embryo from the dorsal source of BM P antagonists (Wilson et al . 1997). A direct demonstration of a gradient of the proteins (either BMPs or their antagonists) has, however, not yet been technically feasible.

\section{Smads can recapitulate morphogen function}

Ectopic expression of Smads by mRNA injection suggests that differential tissue inductions observed with activin or BM P ligands can be mimicked by manipula- tion of Smad activity. Overexpression of full-length Smad2 or its $\mathrm{MH} 2$ domain in prospective ectoderm is sufficient to induce relatively lateral mesodermal markers at low doses and dorsal mesodermal markers at high doses (Baker and Harland 1996; Eppert et al. 1996; Graff et al. 1996), whereas expression of Smad1 or Smad5 at low doses can, like BM P4 stimulation, induce formation of cement $\mathrm{gland}$ and at higher doses induce epidermis in dissociated animal pole cells (Suzuki et al. 1997a; Wilson et al. 1997). In intact embryos expression of Smad1 or Smad5, like BM P2, BM P4, or BM P7, ventral izes the embryo (Liu et al. 1996; Thomsen 1996; Suzuki et al. 1997b). The effects of ectopic Smad expression on patterning still occur even when the upstream receptors are inhibited by overexpression of dominant inhibitory receptor constructs, indicating that additional signals through these receptors are not necessary for ectopic Smads to mimic the patterning effects of their upstream ligands (Eppert et al. 1996; Graff et al. 1996). Carboxyterminal ly truncated Smad4 can sequester receptor-regulated Smads, preventing the formation of viable signaling complexes. Overexpression of this truncated Smad4 can inhibit the induction of mesoderm by activin, supporting a role for Smads in mesodermal specification and/or patterning (Lagna et al. 1996).

Although graded overexpression of the receptor-regulated Smads can in some respects mimic graded ligand stimulation in the specification of early blastomeres, more detailed anal ysis may reveal significant differences in the effects of these different stimuli. As recently pointed out by Dyson and Gurdon (1998), doses of activin high enough to induce the dorsal mesodermal gene goosecoid inhibit expression of the mesoderm response gene Brachyury, which is induced by lower doses of activin (Latinkic et al. 1997). In contrast, high doses of Smad2 expression induce goosecoid and Brachyury concomitantly. This difference may be significant biologically in that in the gastrulating embryo, Brachyury expression is excluded from the dorsal-most region of the mesoderm, the goosecoid-expressing Spemann organizer. That graded overexpression of Smad2 does not recapitulate this pattern may reflect differences in timing of stimulation associated with ectopic expression of Smad 2 by mRN A injection at the 1- to 2-cell stage versus ligand stimulation of dissociated cells at the 1000-cell stage, differences in function between overexpressed, presumably unphosphorylated Smad2 and endogenous Smad2 phosphorylated in response to ligand stimulation, or signals generated by ligand stimulation in addition to activation of Smad2. In any case, the difference between the effects of high-doseactivin stimulation and high-dose Smad2 expression on Brachyury/goosecoid induction at least raise the possibility that a gradient of ligand stimulation in the early embryo may have more complex effects than simply the generation of a gradient of Smad activation.

The morphogen hypothesis: detecting endogenous gradients

The effectiveness of ectopic stimulation of the activin or 
BM P4 signaling pathways by addition of ligands or overexpression of Smads to recapitulate mesodermal and ectodermal patterning is impressive, but several steps remain to establish the role of gradients of Smad activation in early embryonic patterning. The present technical limits of detection of endogenous secreted factor levels in the intercellular space make it very unlikely that a gradient of peptide factor across the embryo will be demonstrable anytime soon. Furthermore, recent work on BM P regulation suggests that the rel evant gradient may not be of the factor itself, but of inhibitors of the factor, and possibly even inhibitors of the inhibitors (Piccolo et al. 1997). One way through the apparent technical morass surrounding the question of endogenous ligand gradients may be provided by our new understanding of the components of the activin and BM P signaling pathways. Because both the type I receptors and the Smads transducing these signals require site specific phosphorylation for activation, the possibility exists of making antibodies directed against these phosphorylated epitopes and using them as histochemi cal probes to assess endogenous spatial and temporal patterns of signal activation. Activation-specific antibodies have been generated for a variety of components of tyrosine kinase signal ing pathways (Epstein et al. 1992), and antiphosphorylated M AP kinase antibodies have been used elegantly to demonstrate spatial and temporal patterns of MAP kinase activation during early embryogenesis (Gabay et al. 1997). Although comparable antibodies for the T GF $\beta$ superfamily signaling pathway have not yet been reported, the nature of type I receptor and Smad activation should be compatible with this approach. Improved methods to examine endogenous signal activation would be invaluable tools for the study of signaling in development; the biochemistry of TGF $\beta$ superfamily receptors and Smads may provide an approach to these methods.

\section{Homologous recombination in mice}

\section{Why is Smad4 not necessary in the embryonic} mesoderm?

Very recently, the knockout of Smad4 and Smad2 by homologous recombination in mice has provided our first information on the necessity of Smads for early vertebrate devel opment, with some unexpected results. Homozygous knockout of Smad4, which previous work in tissue culture cells would predict a complete loss of TGF $\beta$ superfamily signaling, resulted in mice that die early in embryogenesis (Sirard et al. 1998; Yang et al. 1998). These mice exhi bit severe growth retardation during pregastrula development, abnormal visceral endoderm, and no signs of either mesoderm formation or gastrulation. More surprising, in light of previous work demonstrating the necessity of BMP4 (Winnier et al. 1995), type I BM P receptor (BM PRI) (M ishina et al. 1995), and $\mathrm{N}$ odal (Conlon et al. 1994) for normal gastrulation and mesoderm patterning in the mouse, was the observation that the early mesodermal and gastrulation defects were rescued by aggregation of mutant embryos with tetraploid wild-type cells (Sirard et al. 1998). These cells populate only the extraembryonic tissues; that these chimeras show normal early mesodermal development and gastrulation of Smad4 embryonic tissues implies that there is no cell-autonomous necessity for Smad4 in the early embryonic mesoderm. Embryos rescued with wild-type extraembryonic tissue devel op substantial anterior defects after gastrulation, indicating that Smad4 is important in embryonic tissues for normal anterior development.

At this point, there are several possible interpretations of the lack of Smad4 requirement in embryonic tissues for early mesoderm specification and gastrulation. First, although BM P4, Nodal, and a type I BMP receptor are necessary for normal devel opment through gastrulation, it is possible that the primary requirement for these signals, like the Smad4 requirement, is in the extraembryonic tissues. In this case, it would be a second set of non-BM P-, non-Smad4-mediated signals from the extraembryonic tissues that establish and pattern mesoderm in the epiblast prior to gastrulation. The principal argument against this possibility would seem to be that BM PRI is expressed primarily in the epi blast at early gastrulation (M ishina et al. 1995), in which it is required for normal cell proliferation, suggesting that this requirement is autonomous to the epi blast. Additional chimera studies will be necessary to establish more completely where BMP and $\mathrm{N}$ odal signals must be generated and received for normal epiblast patterning. A second possibility is that BM P4/N odal signaling is indeed required in the epibl ast, but there is an as yet uni dentified "Smad4a" that serves a function redundant with Smad4 in the early specification of mesoderm. A third possibility, raised by the observation of Medea-independent effects of Dpp (Wisotzkey et al. 1998), is that in some instances the receptor-regulated Smads can signal in the absence of a Smad4-like heterodimerization partner. A final possibility is that Smad signaling is si mply not requi red for early mesoderm patterning and gastrulation in the mouse, and that the N odal and BM P4 functions observed to be necessary can be transmitted through a different signaling pathway. Detailed characterization of TGF $\beta /$ Smad responsiveness in cell lines derived from Smad4 $4^{-1-}$ mice should begin to distinguish between these possibilities.

\section{Smad2 knockout: another puzzle}

Two independent knockouts of Smad2 have been re ported, and both result in severely defective early embryos that lack embryonic germ layers and recognizable anterior-posteri or pattern (N omura and Li 1998; Wal drip et al. 1998). Additional characterization of the two knockouts reveals, however, significant differences between them. Waldrip et al. (1998) report that Smad2 ${ }^{-1-}$ embryos have relatively normal extraembryonic tissues, whereas the prospective embryonic tissue differentiates as extraembryonic mesoderm, expressing the mesodermal marker Brachyury throughout the epiblast at early gastrula stages. In contrast, N omura and Li (1998) report severe defects in extraembryonic tissues in Smad $2^{-1-}$ ho- 
mozygotes and no expression of Brachyury in the epiblast at gastrulation. In addition, Smad $2^{-1+}$ heterozygotes generated by Waldrip et al . (1998) are phenotypically normal, whereas $20 \%$ of the heterozygotes generated by Nomura and Li (1998) exhibit severe gastrulation defects. The basis for these differences is unclear; similar genetic backgrounds were used, but different regi ons of the Smad2 coding sequence were replaced in each case, and the possibility of the remaining exons encoding a weakly inhibitory or constitutively active form of Smad2 may need to be examined.

In addition to examining the effects of loss of Smad2 throughout the embryonic and extraembryonic tissues, Wal drip et al . (1998) use chimera analysis to examine the role of Smad2 specifically in the extraembryonic tissues. ES cell injection experiments in which the epiblast of a Smad $2^{-1-}$ embryo is populated largely with wild-type ES cells fail to rescue the observed defects, indicating that extraembryonic tissues require $\mathrm{Smad} 2$ to generate signals critical for normal patterning of the embryo. The converse experiment, generation of chimeras in which only the embryonic tissues lack Smad2, has not yet been done, so the question of whether there is an embryonic as well as an extraembryonic requirement for Smad2 in early patterning remains to be answered.

\section{Synthesizing mouse knockouts and frog ectopic expression}

Although important questions remain to be clarified for the Smad2 and Smad4 knockouts, both confirm that Smad signaling is critical for patterning of vertebrate embryos. What was perhaps not expected, however, is the apparent importance of Smad signals in the extraembryonic tissues for normal patterning of the early embryo. M odels for the early establishment and patterning of mesoderm developed from experiments with frog embryos do not address the role of extraembryonic tissues be cause amphibians lack them, making it difficult to synthesize data obtained from ectopic expression of activated or dominant-inhibitory Smads in frogs with those obtained from knockouts in mice into a coherent picture of early mesodermal patterning. Although the general point can be made that Smad signaling is necessary in mice and sufficient in frogs for establ ishment or patterning of the early mesoderm, exactly where and when this Smad-linked patterning occurs in each organism is more difficult to compare. Additional characterization of the necessity for Smads, as well as for TGF $\beta$ superfamily ligands and receptors, in embryonic versus extraembryonic tissues may help to clarify the similarities and differences in Smad-regulated patterning between mammalian and amphibian embryos.

\section{Specificity, feedback regulation, and integration in TGF $\beta$ signaling during development}

The identification of Smads as TGF $\beta$ signal transducers is important in large part because it provides a molecular handle on the dual problems of how different cell types generate different responses to the same signal and of how different types of signals are integrated in their target cells. The fact that Smads can act as direct transcriptional activators, but induce different genes in different cell types, makes understanding of the interaction of cell type-specific cofactors with Smads to generate specific responses central to comprehension of the role of Smads in development. Furthermore, careful analyses of the components of the developmental regulation of individual genes and of the steps involved in specification of distinct tissues make clear that embryonic patterning involves the integration of multiple regulatory signals over time and space. Defining the mechanisms by which Smad signaling interacts with other pathways is therefore essential for understanding Smad function in patterning in vivo.

\section{Specific transcriptional responses to Smad activation-FAST-1 and Tinman}

The ubiquitous expression of signaling Smads during early embryogenesis, and their implication in the mediation of a broad range of responses that depend on the developmental history of the stimulated cell, raise the question of how cell type-specific responses to Smads are generated. The observation of a DNA-binding activity intrinsic to signaling Smads only highlights the question of how different promoters are activated by Smads in different cell types. A major component of the answer to this question presumably lies in other, cell type-specific factors binding to additional regulatory elements in the same promoter. Two examples of how this might work are provided by examination of activin regulation of the early response gene Mix.2 in Xenopus embryos and of $\mathrm{Dpp}$ regulation of tinman in Drosophila.

As discussed above, in the early frog embryo the winged helix transcription factor FAST - 1 targets Smad2 and Smad4 to an enhancer el ement necessary and sufficient for activation of Mix.2 transcription (Huang et al. 1995; Chen et al. 1997; Liu et al. 1997). Level s of FAST-1 mRNA and the competence of embryonic cells to express Mix. 2 in response to activin decline over a similar time span (Chen et al. 1997; Rosa 1989), consistent with the possibility that early embryonic FAST-1 function is necessary for the responsiveness of the Mix.2 enhancer to activin/Smad2 activation; this function is reduced as development progresses, and activin regulation of this early embryo-specific response gene is lost. Ectopic activation of FAST-1 by fusion of its DNA-binding domain to a VP16 transcriptional activator domain activates not just Mix.2 expression but also the full mesodermal transcriptional program regulated by activin ( $M$. Watanabe and $M$. Whitman, in prep.). FAST - 1 may therefore be re sponsible for targeting activated Smad2/Smad4 to a broad set of promoters regulated by activin/TGF $\beta$ signals specifically in early embryos, and activation of these promoters is lost as FAST-1 function declines. Although additional mechanisms are likely to be involved in loss of early developmental competence (Steinbach et al. 1997), the loss of early embryo-specific transcription fac- 
tors that target Smads to early embryo-specific promoters may be one component of this process.

tinman is activated in a broad, mesoderm-specific pattern by the transcription factor Twist early in Drosophila development (Bodmer et al. 1990). During later mesodermal patterning, tinman expression is restricted to the dorsal mesoderm; this later expression is dependent on Dpp signaling (Frasch 1995). Dpp induces tinman in the mesoderm, but not in the ectoderm, in which $\mathrm{Dpp}$ is also clearly active in patterning. M ad and M edea bind to the tinman promoter in vitro, but these binding sites are not sufficient for induction in vivo (Xu et al. 1998). The basis for the mesoderm specific action of $\mathrm{Dpp} / \mathrm{Mad} / \mathrm{M}$ edea on tinman regulation appears to be Tinman protein itself, which binds at sites adjacent to the $M$ ad/M edea sites and synergizes with $M$ ad/ $M$ edea to activate tinman transcription. At this stage, there is no evidence that $M$ ad or M edea interact directly with Tinman (as is the case for Smad2/Smad4 and FAST -1); synergy presumably occurs through interaction with the basal transcription apparatus. Ectopic expression of Tinman in the ectoderm is results in Dpp induction of tinman transcription in ectoderm, confirming that Tinman is sufficient to act as a determinant of the normal mesoderm-specific response. In addition to the positive requirement for Tinman, there are additional negative regulatory sites that suppress tinman expression in the ectoderm, indicating that endogenous regulation involves tissue-specific repressors as well as activators. Although complete regulation of the spatial and temporal pattern of developmental genes is likely to involve complex sets of binding sites and transcription factors (Arnone and Davidson 1997), the undoubtedly simplified cases of regulation by FAST-1 and Tinman provide examples of how ubiquitous Smads transduce tissue-specific transcriptional responses.

\section{Feedback regulation by inhibitory Smads}

Following the discovery of Smads as signal transducers, several Smads were identified that act as inhibitors of TGF $\beta$ superfamily signaling (Hayashi et al. 1997; Imamura et al. 1997; Nakao et al. 1997a; Tsuneizumi et al. 1997). Smad6 and Smad7, and Dad, lack the carboxyterminal phosphorylation sequence and have $\mathrm{MHI}$ domains that are highly divergent from the signaling Smads. Overexpression of Smad6 or Smad7 can block signaling by multiple members of the TGF $\beta$ superfamily (Hayashi et al. 1997; Imamura et al. 1997; $N$ akao et al. 1997a; Hata et al. 1998). In mammalian tissue culture cells and amphibian embryos, Smad7 [a Xenopus Smad7 homolog has been independently named Smad8 ( $\mathrm{Na}$ kayama et al. 1998)] blocks BM P signaling at low doses and activin/TGF $\beta$ signaling at higher doses (C asellas and Hemmati-Brivanlou 1998). Conflicting results have been reported for the specificity of inhibition by Smad6. It may inhibit both BMP and TGF $\beta$ signaling (Imamura et al. 1997), but inhibition of TGF $\beta$ signaling is weak and may occur only at very high doses of Smad6 (Hata et al. 1998). Ectopic expression of dad in the Drosophila wing disc inhibits signaling by Dpp and can block BMP signaling when expressed in Xenopus embryos (T suneizumi et al. 1997). Whether Dad is a selective inhibitor of BM $P$ signaling or might al so inhibit activin/TGF $\beta$ signaling at higher doses has not been examined.

Two mechanisms have been proposed for the action of inhibitory Smads. Expression of Smad7 inhibits the receptor-regulated phosphorylation Smad2 or Smad3, whereas Smad6 can inhibit receptor-regulated phosphorylation of Smad1 and Smad2 but not Smad3 (Hayashi et al. 1997; Imamura et al. 1997; $N$ akao et al. 1997a) (Fig. 3). These observations indicate that Smad6 and Smad7 can inhibit transmission of regulatory signals between the type I receptors and the pathway-specific signaling Smads. This interpretation is supported by data showing that Smad6 and Smad7 can interact stably with type I receptors (Hayashi et al. 1997; Imamura et al. 1997; N akao et al. 1997a), suggesting that they function as competitive inhibitors of type I receptor phosphorylation of receptor-regulated Smads. For Smad6, however, an additional inhibitory function has been found in its ability to bind to Smad1, preventing the Smad1 from binding Smad4 and thereby sequestering it from its normal signal ing function (Hata et al. 1998). Co-overexpression of Smad4 with Smad6 can rescue BM P signaling in COS cells, supporting the interpretation that in this system Smad6 acts to limit Smad4 availability (Hata et al. 1998). Data on both the function and mechanism of action of inhibitory Smads have come entirely from overexpression studies. At this point it is difficult to resolve to what extent the specificity of inhibition of different TGF $\beta$ superfamily signal ing pathways, or of the intracellular target for inhibition (i.e., receptor sequestration or Smad1 sequestration by Smad6), is a function of the levels of expression of the various transducing and inhibitory components of the signaling pathway. It is clear, however, that inhibitory Smads can differentially target

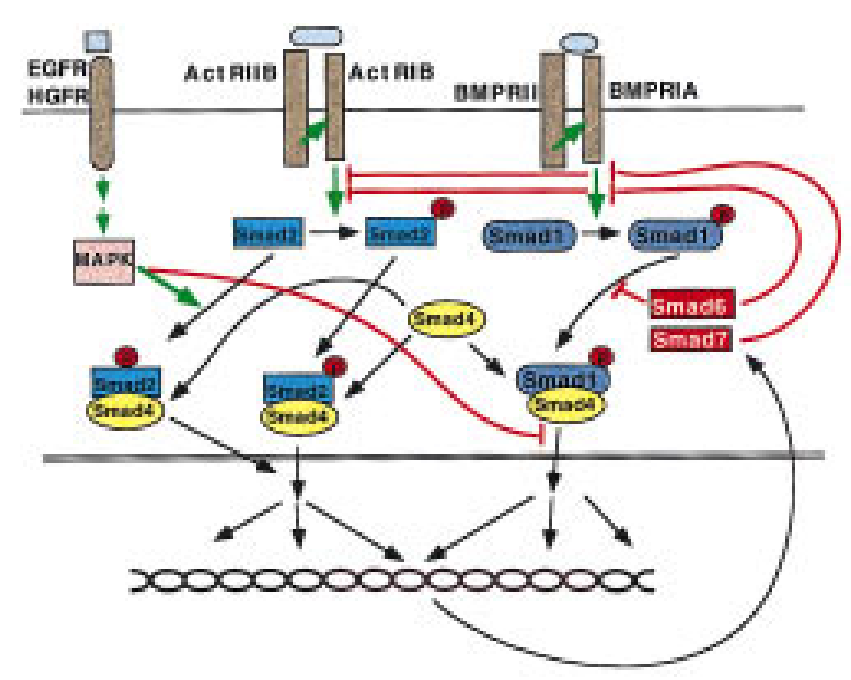

Figure 3. Multiple pathways for Smad regulation. Schematic of currently understood intracellular pathways for regulation of Smads. Green arrows denote positive regulatory interactions; red bars denote inhibitory interactions. 
distinct subsets of the TGF $\beta$ superfamily of signals, and this seems likely to be significant for their function in vivo.

Several of the inhibitory Smads have been shown to be induced by the ligands they inhibit ( $\mathrm{N}$ akao et al. 1997a; Tsuneizumi et al. 1997; N akayama et al . 1998), as well as by other stimuli (Topper et al. 1997). This implies that they function in a negative feedback loop, perhaps limiting the duration of ligand stimulation. In Drosophila, cells that would normally express Dad in the wing disc no longer do so when they lack upstream components of the Dpp signaling pathway, indicating that Dpp signals are necessary for expression of dad in vivo (T suneizumi et al. 1997). In Xenopus embryos, Smad7 (initially named Smad8) and BM P4 are coexpressed in the prospective ectoderm (N akayama et al. 1998). Endogenous Smad7 expression is inhibited by blockade of endogenous BMP signaling, again demonstrating that BMP4 positively regulates Smad7 in vivo (Nakayama et al. 1998). Early ectodermal cells are sensitive to ectopic BMP stimulation, however, indicating that Smad7 is not present at levels sufficient to prevent BMP signaling in this tissue. Similarly, the Dpp-dependent expression of spalt and omb in the Drosophila wing disc is not prevented by endogenous Dad expression in the same cells.

Signal regulation by inhibitory Smads in vivo may well be more subtle than a simple feedback "off" switch: BMP signals during early embryogenesis may induce Smad7 as an attenuator of ectodermal sensitivity to subsequent signals, rather than as a strict inhibitor. Given the ability of inhibitory Smads to inhibit different TGF $\beta$ signaling pathways at different doses, it is al so possible that these Smads act as cell-autonomous modifiers to al ter the rel ative strengths of different TGF $\beta$ superfamily signals. In cases where Smad1 and Smad2 activation evoke quite different responses (e.g., early frog blastomeres), expression of a preferential inhibitor of one pathway (e.g., Smad6) might serve as an important modifier of devel opmental responses. In addition, if TGF $\beta$ s signal through pathways in addition to those involving Smads (Yamaguchi et al. 1995), inhibitory Smads may modulate responses by inhibiting the Smad component, but not the non-Smad component, of the response.

During early embryogenesis, localized inhibition of TGF $\beta$ superfamily signaling has emerged as a patterning mechanism as important as activation of signaling (for review, see Ferguson 1996). Extracellular inhibitors of BMPs, conserved structurally and functionally between vertebrates and Drosophila, pattern the dorsal-ventral body axis by local antagonism of BM P or Drosophila D pp (Holley et al. 1995; Schmidt et al. 1995a; Piccolo et al. 1996). In some cases, these extracellular inhibitors can themselves be induced by TGF $\beta$ superfamily signals (Green et al. 1994; Sasai et al . 1994). The identification of Smad6, Smad7, and Dad as inducible intracellular inhibitors of TGF $\beta$ signaling suggests that pattern regulation could involve a comparable intracellular mechanism for localized signal inhibition. Further characterization of the specificity of inhibitory Smad action and the regulation of their expression should prove to be an important component of understanding how TGF $\beta$ signaling is patterned across developing tissues.

\section{Cross regulation and integration of Smad signals}

Patterning in vivo by TGF $\beta$ s involves not only the induction of specific transcriptional responses by Smads but al so the modulation of these responses by cross talk and integration with other signaling pathways. N umerous examples of interaction between signal ing pathways in both vertebrate and invertebrate embryos are known; examination of Smad regulation provides an intracellular focal point for understanding how such cross talk works. Our present knowledge of intracellular regulation/integration of Smad signals can be divided into two general categories: (1) pathway cross talk in the cytoplasm and (2) signal integration at target enhancers/promoters.

\section{Cross talk in the cytoplasm}

Several examples of regulation of Smad signaling by interaction between signaling pathways in the cytoplasm have been reported: (1) cross interference between BM P and activin signaling in Xenopus embryos; (2) inhibition of Smad1 by EGF signaling; (3) inhibition of Smad1/ Smad5 signaling by inhibition of TAK1; (4) activation of Smads by tyrosine kinase signaling; and (5) physical interaction of Smads with calmodulin. Given the relative youth of the Smad field this is undoubtedly only a foreshadowing of a much larger set of regulations yet to be found, but these examples begin to provide an indication of the range of possibilities.

Activin and BMP Smad1 and Smad2 signals have distinct and, to some extent opposed, effects in early Xenopus embryos. Smadl overexpression/activation ventralizes embryonic mesoderm, whereas Smad2 overexpression/activation induces dorsal mesodermal markers (Graff et al. 1996). Inhibition of BMP signaling in the ventral marginal zone of early embryos results in ectopic formation of dorsal mesoderm (Graff et al. 1994; Suzuki et al. 1994), suggesting that endogenous BMP signaling in the lateral and ventral mesoderm antagonizes the specification of dorsal mesoderm by an activin/Vg-1 like signal. Given that BMPs, activin, and $\mathrm{Vg}-1$ all share Smad4 as a common component of their respective signaling pathways, one possible point at which these pathways could cross interfere is through competition for Smad4. Candia et al. (1997) have demonstrated that the observed antagonism between BM Ps and acti vin/ Vgl occurs at a postreceptor step and that this inhibition is reciprocal, that is, and BMP2/4 can inhibit expression from an activin/ $\mathrm{Vg}$-1 responsive reporter and, activin or Vgl can inhibit expression from a BM P-responsive re porter. Expression of excess Smad4 relieves the inhibition of the activin/ $\mathrm{Vg}-1$ responsive reporter by BMPs, indicating that under some circumstances TGF $\beta$ superfamily signals that use different pathway-specific Smads may complete for Smad4, and thus cross-modulate acti- 
vation of downstream targets. The relief of cross-interference between BMPs and activin by Smad4 was observed under conditions of ectopic ligand addition-the extent to which endogenous signaling is in fact limited by Smad4 avail ability is unknown, as are the parameters that determine which TGF $\beta$ signaling pathway "wins" under endogenous conditions of competition. In addition, it is clear that BM Ps and activin/Vg-1 each induce genes that themselves can cross interfere with patterning specified by the other pathway (Cho et al. 1991; Gawantka et al. 1995; Latinkic et al. 1997); therefore, the observed antagonism in patterning is likely to occur at downstream steps as well as at the step of competition between pathways for Smad4.

EGF and Smad1 In addition to the carboxy-terminal sites in Smad1, Smad2, Smad3, and Smad5 identified as critical for positive regulation by type I receptors, Smads contain multiple additional potential phosphorylation sites, including consensus predicted MAPK sites. In the case of Smad1, several such sites in the region linking the $\mathrm{MH} 1$ and $\mathrm{MH} 2$ domains can be phosphorylated by MAP kinase after cell stimulation by EGF (Kretzschmar et al. 1997a). These linker phosphorylations inhibit nuclear local izati on of Smad1 and transcripti onal activation by a Smad1-Gal 4 fusion construct. Linker phosphorylation by MAP kinase occurs independently of BM $P$ receptor regulation of carboxy-termi nal phosphorylation and does not inhibit Smad1-Smad4 association. It does, however, prevent nuclear localization of the Smad1/Smad4 complex. The molecular basis for this inhibition by linker phosphorylation is not known. MAPKdependent phosphorylation of the Smad1 linker provides a mechanism by which receptor tyrosine kinases or other agents that activate MAPK can antagonize BMP signaling. Physiological examples of such antagonism exist (see, e.g., N iswander and M artin 1993; Ganan et al. 1996; N eubuser et al . 1997), whether Smad1 linker phosphorylation is in fact a major mechanism mediating this antagonism in vivo remains to be shown.

TAK1 and Smads1/5 TAK1 (TGF $\beta$-activated kinase) was originally identified as a TGF $\beta$ or BMP-activated MAP kinase kinase kinase (MAPKKK) that can regulated a T GF $\beta$ responsive promoter ( $Y$ amaguchi et al. 1995). In early frog embryos, ectopic activation of TAK1, like BM Ps or ectopic expression of Smad1 or Smad5, can induce ventral mesodermal markers (Shibuya et al. 1998). Furthermore, expression of a kinase-dead inhibitory TAKI (TAK1KN) construct inhibits gene induction by BM P or Smad1/5, but not gene induction by activin. The molecular basis for this functional interaction between TAK1 and Smad1/Smad5 is unknown. These observations do imply, however, that a positive regulator of a MAPK pathway is necessary for normal functioning of Smad1/Smad5 in the early embryo, in contrast to the inhibitory relationship between Smadl and MAPK reported in the previous example (EGF and Smad1). The MAP/SAP kinase family is by now quite large, with a complex and incompletely understood set of regulators and targets (Cohen 1997); understanding regulatory interactions between this family and the Smads will re quire a detailed knowledge of the sites on Smads phosphorylated by MAP/SAP kinases and the specific pathways and kinases regulating these phosphorylations in vivo.

HGF and Smad2 Still another link between MAPK signaling and Smad activation has come from the report that in several cell types HGF or EGF can activate Smad signaling, apparently by positive regulatory phosphorylation of Smad2 (de Caestecker et al. 1998). EGF, HGF, and TGF $\beta$ all activate the standard TGF $\beta$ reporter, 3TPLux, in a Smad4-dependent manner in the breast cancer cell line MDA-MB-468, indicating that all three factors require a Smad pathway for signal ing to this promoter in these cells. All three factors stimulate phosphorylation of Smad2, but only TGF $\beta$ stimulation leads to phosphorylation of the carboxy-terminal serines. The MEK1 inhibitor PD 98059 inhibits the EGF and HGF, but not TGF $\beta$ phosphorylation of Smad2, indicating that the tyrosine kinase receptors use a MAPK family member to activate Smad2. The sites of this activating phosphorylation has not been mapped, and therefore it is not yet known whether regulation through M APK is direct. Like the studies of TAK1, these observations of the positive regulation of Smad2 by a MAPK contrast sharply with the observations that MAPK inhibits Smadl but are certainly not mutually exclusive. There are a wide range of examples in which TGF $\beta$ superfamily and MAPKcoupl ed signal s synergize rather than antagonize one another (see, for examples, LaBonne et al. 1995; Oft et al. 1996); therefore, the potential physiological relevance of the positive effects of MAPK signaling on Smads seems at least as plausible as the inhibitory effects. At this point it is difficult to safely general ize about Smad regulation by MAPK: An activating signal for Smadl may be inhibitory for Smad2; until we know more about the sites and structural effects of phosphorylation of Smads by MAPKs it will be difficult to draw general conclusions about how or when the MAPK pathway(s) modulate the Smad pathway. N evertheless, the observed positive and negative MAPK/Smad regulations will be important targets for investigation of the physiological interactions between these pathways.

Calmodulin Recently, the identification of calmodulin as a Smad binding protein has suggested another potential mode for regulation of Smad signaling (Zimmerman et al. 1998). Calmodul in associates in vitro with Smad1Smad4 in a calcium-regulated manner through a site near the amino terminus. In intact cells, inhibition of calmodulin enhances activin induction of the 3TP-Lux reporter, whereas calmodul in overexpressi on inhibits activin induction, suggesting that calmodulin might inhibit Smad function. The potential effects of cal modulin manipulation are sufficiently complex in vivo, however, that much additional work will be necessary to determine to what extent di rect binding of signaling Smads by calmodulin modulates their function. Given the wide 
range of stimuli that can regulate calmodulin function (N iki et al. 1996), direct regulation of Smads by calmodulin would open up a very broad set of potential interactions between TGF $\beta$ s and other physiological signals.

\section{Pathway convergence at a target promoter}

Activin and Wnts In both Drosophila and Xenopus, TGF $\beta$ and Wnt family-generated signals have been shown to interact during embryonic patterning (Grimm and Pflugfelder 1996; for review, see Harland and Gerhart 1997). In Xenopus, the cloning of the promoter for goosecoid provides an example of how this interaction works (Watabe et al. 1995). Two distinct promoter elements confer responsiveness to Wnt and activin signal s, and act synergistically together to activate goosecoid transcription. In the case of the distal element (DE), which responds to activin, activin stimulates Smad2 and Smad4 association with an as yet unidentified transcription factor that binds to the element. Wnt signal ing does not appear to affect the activation of the Smads or regulation of this element directly but, rather, regulates expression through the transcription factor complex of $\beta$ catenin/LEF-1, of the homeobox transcription factors Twin and Siamois (Brannon et al. 1997; Laurent et al. 1997). These factors then bind to a site, the proximal element, adjacent to the DE on the promoter (Laurent et al. 1997). The localization of goosecoid transcription to the organizer therefore appears to be regulated by the integration at the promoter of binding of a Smad2/ Smad4-containing transcription complex and a Siamois/ Twin transcription factor. Whether this binding is fully independent or, cooperative, to some extent, is not known.

Activin and FGF Induction of a range of early mesodermal responses by activin/Vg-1 signals, as well as by ectopically expressed Smad2, requires an endogenous FGF signal (Cornell and Kimelman 1994; LaBonne and Whitman 1994; M. Lee and M. Whitman, unpubl.). MAPK is a critical component of this requirement: Inhibition of MAPK mimics the block to FGF in preventing transcriptional induction by activin, ectopic activation of MAPK rescues activin induction of mesoderm in the presence of a block to FGF, and endogenous MAPK activity is blocked by blocking FGF signaling (LaBonne et al. 1995; LaBonne and Whitman 1997). MAP kinase activation does not appear either to stimulate or block Smad2 activation in early frog blastomeres but is required for downstream phenotypic effects of Smad2 expression ( $M$. Lee and $M$. Whitman, unpubl.). Activin stimulation of the FAST-1-Smad2-Smad4 complex (ARF) occurs even in the absence of an FGF/M APK signal and is unaffected by ectopic activation of MAPK (Huang et al. 1995). This permits the requirement for FGF/MAPK signaling in this case to be mapped downstream of (or parallel to) Smad activation. Interestingly, transcriptional activation of the ARE reporter, to which ARF binds, is unaffected by blockade of FGF/MAPK, even though activin regulation of the larger Mix.2 promoter from which the
ARE was isolated is blocked by inhibition of FGF signaling (M. Watanabe and $M$. Whitman, in prep.). This would seem to indicate that signals from the activin and FGF signaling pathways are integrated at discrete regulatory elements in the Mix.2 promoter, with the ARE mediating a Smad2-linked signal and an as yet unidentified element mediating a signal from MAPK. Comparison of the role of cross talk between MAPK and activin signals in early mesoderm induction to the MAPK interactions with Smadl signaling in COS cells (Kretzschmar et al. 1997a) and Smad2 signaling in MDA-MB-468 cells (de Caestecker et al. 1998) suggests that there are multiple points at which the MAPK and Smad pathways can interact.

\section{Conclusions}

In the context of the morphogen hypothesis, the fact that manipulation of Smad signal ing pathways is sufficient to specify multiple tissue types is intriguing, but other evidence from early embryos indicates that there is much more to developmental specification than gradients of Smad signaling. Graded stimulation by individual ectopic signals in vitro may mimic processes that are specified in vivo by the intersection of multiple signals: High levels of Smad2 signaling are sufficient to induce genes specific to the Spemann organizer in isolated ectoderm (Green et al. 1992; Baker and Harland 1996; Graff et al. 1996), but a variety of experiments indicate that formation of the endogenous organizer depends on the intersection of several signals, including both Wnt/ $\beta$-catenin and activin/Vg-1 Smad2-likesignals (Watabe et al. 1995), as well as the local inhibition of BM P signals (for review, see Harland and Gerhart 1997). In addition, there is a great deal of evidence indicating that patterning involves temporally complex, often labile, steps. In the case of the Xenopus cement gland, for example, several studies have demonstrated that a defined dose of BMP4, Smad1, or Smad5 is sufficient to specify this structure. However, a long history of dissection and transplantation experiments in Xenopus gastrulae have elegantly demonstrated that specification of endogenous cement $\mathrm{gland}$ is a highly spatially and temporally dynamic process that is not easily explained by a simple standing gradient of Smad1 activation (Sive et al. 1989; Bradley et al. 1996). Similarly, Knecht and Harland (1997) have shown that although Noggin inhibition can induce a dorsal brain marker in a graded fashion, patterning of this marker in explants is a function of both the age-dependent competence and cell motility of the target tissue, suggesting multiple dynamic components to neural patterning at this tissue. Manipulation of Smads by ectopic expression, null mutation, and knockout have proven to be powerful tools for establishin what Smads can do and what they are required for in early development, but this will be only a first step toward elucidating how they partici pate in the multicomponent, temporally dynamic processes that establish the pattern of the early embryo. Characterization of how feedback pathways and regulation by non-TGF $\beta$ signals (summarized in Fig. 3) actually 
modulate Smad signals in vivo, identification of localized transcription factors that confer tissue specific responses to Smads, and the development of methods to measure the spatial and temporal distributions of activated Smads in embryos will be critical components of a full understanding of how TGF $\beta$ s may function as morphogens during early embryogenesis.

\section{Acknowledgments}

I thank Carole LaBonne, Paul Wilson, Laurel Raftery, Michelle Lee, and anonymous reviewers for valuable comments on the manuscript. The author is supported by grants from the $\mathrm{Na}$ tional Institute of Child Health and Development.

\section{References}

Abdollah, S., M. Macías-Silva, T. Tsukazaki, H. Hayashi, L. Attisano, and J.L. Wrana. 1997. T $\beta R$ I phosphorylation of Smad2 on Ser465 and Ser467 is required for Smad2-Smad4 complex formation and signaling. J. Biol. Chem. 272: 2767827685.

Arnone, M. and E. Davidson. 1997. The hardwiring of development: Organization and function of genomic regulatory systems. Development 124: 1851-1864.

Attisano, L. and J. Wrana. 1998. Mads and Smads in TGF $\beta$ signalling. Curr. Opin. Cell Biol. 10: 188-194.

Baker, J.C. and R.M. Harland. 1996. A novel mesoderm inducer, $M$ adr2, functions in the activin signal transduction pathway. Genes \& Dev. 10: 1880-1889.

Bodmer, R., L. Jan, and Y. Jan. 1990. A new homeobox-containing gene, msh-2, is transiently expressed early during mesoderm formation of Drosophila. Development 110: 661-669.

Bradley, L., D. Wainstock, and H. Sive. 1996. Positive and negative signals modulate formation of the Xenopus cement gland. Development 122: 2739-2750.

Brannon, M., M. Gomperts, L. Sumoy, R. M oon, and D. Kimelman. 1997. $\beta$-Catenin/XTcf-3 complex binds to the siamois promoter to regulate dorsal axis specification in Xenopus. Genes \& Dev. 11: 2359-2370.

Candia, A., T. Watabe, S. Hawley, D. Onichtouk, Y. Zhang, R. Derynck, C. Niehrs, and K. Cho. 1997. Cellular interpretation of multiple TGF $\beta$ signals: Intracellular antagonism be tween activin/BVgl and BMP-2/4 signaling mediated by Smads. Development 124: 4467-4480.

Carcamo, J., F. Weis, F. Ventura, R. Wieser, J.L. Wrana, L. Attisano, and J. M assagué. 1994. Type I receptors specify growthinhibitory and transcriptional responses to transforming growth factor beta and activin. Mol. Cell. Biol. 14: 38103821.

Casellas, R. and A. Hemmati-Brivanlou. 1998. Xenopus Smad7 Inhibits both the Activin and BM P pathways and acts as a neural inducer. Dev. Biol. 198: 1-12.

Chen, X., M.J. Rubock, and M. Whitman. 1996. A transcriptional partner For M ad proteins in TGF- $\beta$ signalling. Nature 383: 691-696.

Chen, X., E. Weisberg, V. Fridmacher, M. Watanabe, G. N aco, and M. Whitman. 1997. Smad4 and FAST-1 in the assembly of activin-response factor. Nature 389: 85-89.

Cho, K.W., B. Blumberg, H. Steinbesser, and E. DeRobertis. 1991. M olecular nature of Spemann's Organizer: The role of the Xenopus homeobox gene goosecoid. Cell 67: 1111-1120.

Cohen, P. 1997. The search for physiological substrates of MAP and SAP kinases in mammalian cells. Trends Cell Biol.
7: 353-361.

Conlon, F., K. Lyons, N. Takaesu, K. Barth, A. Kispert, B. Hermann, and E. Robertson. 1994. A primary requirement for nodal in the formation and maintenance of the primitive streak in the mouse. Development 129: 1919-1928.

Conlon, F.L., C.M. Jones, and J.C. Smith. 1996. From mouse to frogs-Identification and functional analyses of genes required for induction and patterning of the mesoderm. Semin. Cell Dev. Biol. 7: 95-101.

Cornell, R.A. and D. Kimelman. 1994. Activin-mediated mesoderm induction requires FGF. Development 120: 453-462.

Dale, L., G. Howes, B.M.J. Price, and J.C. Smith. 1992. Bone morphogenetic protein 4: A ventralizing factor in Xenopus development. Development 115: 573-585.

Das, P., L. M aduzia, H. Wang, A. Finelli, S. Cho, M. Smith, and R. Padgett. 1998. The Drosophila gene Medea demonstrates the requirement for different classes of Smads in dpp signaling. Development 125: 1519-1528.

de Caestecker, M.P., P. Hemmati, S. Larisch-Bloch, R. Ajmera, A.B. Roberts, and R. J. Lechleider. 1997. Characterization of functional domains within Smad4/DPC4. J. Biol. Chem. 272: 13690-13696.

de Caestecker, M., W. Parks, C. Frank, P. Castagnino, D. Bottaro, A. Roberts, and R. Lechleider. 1998. Smad2 transduces common signals from receptor serine-threonine and tyrosine kinases. Genes \& Dev. 12: 1587-1592.

Dennler, S., S. Itoh, D. Vivien, P. ten Dijke, S. Huet, and J. Gauthier. 1998. Direct binding of Smad3 and Smad4 to critical TGF $\beta$ inducible el ements in the promoter of human plasminogen activator inhibitor-type I gene. EMBO J. 17: 30913100.

Derynck, R. and X.-H. Feng. 1997. TGF $\beta$ receptor signaling. Biochim. Biophys. Acta 1333: F105-F150.

Derynck, R., W.M. Gelbart, R.M. Harland, C.-H. Heldin, S.E. Kern, J. Massagué, D.A. M elton, M. Moldzik, R.W. Padgett, A.B. Roberts, J. Smith, G.H. Thomsen, B. Vogelstein, and X.-F. Wang. 1996. Nomenclature: Vertebrate mediators of TGF- $\beta$ family signals. Cell 87: 173.

Dick, A., W. Risau, and H. Drexler. 1998. Expression of Smad1 and Smad2 during embryogenesis suggests a role in organ development. Dev. Dyn. 211: 293-305.

Dohrmann, C.E., A. Hemmati-Brivanlou, G.H. Thomsen, A. Fields, T. Woolf, and D. Melton. 1993. Expression of activin mRNA during early development in Xenopus laevis. Dev. Biol. 157: 474-483.

Dosch, R., V. Gawantka, H. Delius, C. Blumenstock, and C. Niehrs. 1997. Bmp-4 acts as a morphogen in dorsoventral mesoderm patterning in Xenopus. Development 124: 23252334.

Dyson, S. and J. Gurdon. 1998. The interpretation of position in a morphogen gradient as revealed by occupancy of activin receptors. Cell 93: 557-568.

Eppert, K., S.W. Scherer, H. Ozcelik, R. Pirone, P. Hoodless, H. Kim, L.C. Tsui, B. Bapat, S. Gallinger, I.L. Andrulis, G.H. Thomsen, J.L. Wrana, and L. Attisano. 1996. Madr2 maps to $18 q 21$ and encodes a Tgf- $\beta$-regulated Mad-related protein that is functionally mutated in colorectal carcinoma. Cell 86: 543-552.

Epstein, R., B. Druker, T. Roberts, and C. Stiles. 1992. Synthetic phosphopeptides yield activation-specific antibodies to the c-erbB2 receptor. Proc. Nat. Acad. Sci. 89: 10435-10439.

Estevez, M., L. Attisano, J. Wrana, P. Albert, J. M assagué, and D. Riddle. 1993. The daf-4 gene encodes a bone morphogenetic protein receptor controlling $C$. el egans dauer larva development. Nature 365: 644-649.

Ferguson, E. 1996. Conservation of dorsal-ventral patterning in 
arthropods and chordates. Curr. Opin. Genet. Dev. 6: 424431.

Ferguson, E. and K. Anderson. 1992. Decapentaplegic acts as a morphogen to organize dorsal-ventral patern in the Drosophila embryo. Cell 54: 95-104.

Frasch, M. 1995. Induction of visceral and cardiac mesoderm by ectodermal Dpp in the early Drosophila embryo. Nature 374: 464-467.

Gabay, L., R. Seger, and B. Shilo. 1997. MAP kinase in situ activation atlas during Drosophila embryogenesis. Development 124: 3535-3541.

Ganan, Y., D. M acías, M. Duterque-Coquillaud, M. Ros, and J. Hurle. 1996. Role of TGF $\beta$ S and BM Ps controlling the position of the digits and the areas of interdigital cell death in the developing chick limb autopod. Development 122: 2349-2357.

Gawantka, V., H. Delius, K. Hirschfeld, C. Blumenstock, and C. $\mathrm{N}$ iehrs. 1995. Antagonizing the Spermann Organizer-Role of the homeobox gene Xvent-1. EMBO J. 14: 6268-6279.

Gel bart, W. 1989. The decapentapl egic gene: A TGF $\beta$ homolog controlling pattern formation in Drosophila. Development (Suppl.) 107: 65-74.

Graff, J.M., R.S. Thies, J.J. Song, A.J. Cel este, and D.A. M elton. 1994. Studies with a Xenopus BMP receptor suggest that ventral mesoderm-inducing signals override dorsal signals in vivo. Cell 79: 169-179.

Graff, J.M., A. Bansal, and D.A. Melton. 1996. Xenopus Mad proteins transduce distinct subsets of signals for the Tgf- $\beta$ superfamily. Cell 85: 479-487.

Graham, A. and A. Lumsden. 1996. Patterning the neural crest. Biochem. Soc. Symp. 62: 77-83.

Green, J.B.A. and J.C. Smith. 1990. Graded changes in dose of a Xenopus activin A homologue elicit stepwise transitions in embryonic cell fate. Nature 347: 391-394.

Green, J.B.A., H.V. N ew, and J.C. Smith. 1992. Responses of embryonic Xenopus cells to activin and FGF are separated by multiple dose thresholds and correspond to distinct axes of the mesoderm. Cell 71: 731-739.

Green, J.B., J.C. Smith, and J.C. Gerhart. 1994. Slow emergence of a multithreshold response to activin requires cell-contactdependent sharpening but not prepattern. Development 120: 2271-2278.

Grimm, S. and G. Pflugfelder. 1996. Control of the gene optomotor-blind in Drosophila wing development by decapentaplegic and wingless. Science 271: 1601-1604.

Gurdon, J.B., P. Harger, A. Mitchell, and P. Lemaire. 1994. Activin signaling and response to a morphogen gradient. $\mathrm{Na}$ ture 371: 487-492.

Harland, R. and J. Gerhart. 1997. Formation and function of Spemann's Organizer. Annu. Rev. Cell Dev. Biol. 13: 611667.

Hata, K., R.S. Lo, D. Wotton, G. Lagna, and J. Massagué. 1997. Mutations increasing autoinhibition inactivate tumour suppressors Smad2 and Smad4. Nature 388: 82-87.

Hata, A., G. Lagna, J. Massagué, and A. Hemmati-Brivanlou. 1998. Smad6 inhibits BM P/Smad1 signaling by specifically competing with the Smad4 tumor suppressor. Genes \& Dev. 12: 186-197.

Hayashi, H., S. Abdollah, Y. Qui, J. Cai, Y. Xu, B. Grinnell, M. Richardson, J. Topper, M. Gimbrone, J. Wrana, and D. Fal b. 1997. The Mad-related protein Smad7 associates with the TGF- $\beta$ receptor and functions as an antagonist of TGF- $\beta$ signaling. Cell 89: 1165-1173.

Heldin, C.-H., K. Miyazono, and P. ten Dijke. 1997. TGF $\beta$ signalling from cell membrane to nucleus through Smad proteins. Nature 390: 465-471.
Hemmati-Brivanlou, A. and D.A. Melton. 1992. A truncated activin receptor dominantly inhibits mesoderm induction and formation of axial structures in Xenopus embryos. Nature 359: 609-614.

Hemmati-Brivanlou, A. and G.H. Thomsen. 1995. Ventral mesodermal patterning in Xenopus embryos-Expression patterns and activities of Bmp-2 and Bmp-4. Dev. Genet. 17: 7889.

Holley, S., P. Jackson, Y. Sasai, B. Lu, E.D. Robertis, F. Hoffman, and E. Ferguson. 1995. A conserved system for dorsal-ventral patterning in insects and vertebrates involving short gastruIation and chordin. Nature 376: 249-253.

Hoodless, P.A., T. Haerry, S. Abdollah, M. Stapleton, M.B. O'Connor, L. Attisano, and J.L.Wrana. 1996. MADR1, a MAD-related protein that functions in BM P2 signaling pathways. Cell 85: 489-500.

Huang, H.C., L.C. M urtaugh, P.D. Vize, and M. Whitman. 1995. Identification of a potential regulator of early transcriptional responses to mesoderm inducers in the frog embryo. EMBO J. 14: 5965-5973.

Hudson, J., S. Podos, K. Keith, S. Simpson, and E. Ferguson. 1998. Drosophila M edea gene is required downstream of dpp and encodes a functional homolog of human Smad4. Development 125: 1407-1420.

Imamura, T., M. Takase, A. Nishihara, E. Oeda, J.-I. Hanai, M. Kawabata, and K. M iyazono. 1997. Smad6 inhibits signalling by the TGF $\beta$ superfamily. Nature 389: 622-626.

Jones, C.M., K.M. Lyons, P.M. Lapan, C. Wright, and B. Hogan. 1992. DVR-4 (bone morphogenetic protein-4) as a posteroventralizing factor in Xenopus mesoderm induction. Development 115: 639-647.

Kim, J., K. Johnson, H. Chen, S. Carroll, and A. Laughon. 1997. Drosophila Mad binds to DNA and directly mediates activation of vestigial by Decapentapl egic. N ature 388: 304-308.

Kingsley, D. 1994. The TGF $\beta$ superfamily: N ew members, new receptors, and new genetic tests of function in different organisms. Genes \& Dev. 8: 133-146.

Knecht, A. and R. Harland. 1997. M echanisms of dorsal-ventral patterning in noggin induced neural tissue. Development 124: $2477-2488$.

Kretzschmar, M., J. Doody, and J. Massagué. 1997a. Opposing BM P and EGF signalling pathways converge on the TGF- $\beta$ family mediator Smad1. Nature 389: 618-622.

Kretzschmar, M., F. Liu, A. Hata, J. Doody, and J. Massagué 1997b. The T GF- $\beta$ family mediator Smad1 is phosphorylated directly and activated functionally by the BMP receptor kinase. Genes \& Dev. 11: 984-995.

LaBonne, C. and M. Whitman. 1994. Mesoderm induction by activin requires FGF-mediated intracellular signals. Development 120: 463-472.

-_- 1997. Localization of M AP kinase activity in early Xenopus embryos: Implications for endogenous FGF signaling. Dev. Biol. 183: 9-20.

LaBonne, C., B. Burke, and M. Whitman. 1995. Role of MAP kinase in mesoderm induction and axial patterning during Xenopus development. Development 121: 1475-1486.

Lagna, G., A. Hata, A. Hemmati-Brivanlou, and J. Massagué. 1996. Partnership between DPC 4 and SMAD proteins in TGF- $\beta$ signalling pathways. Nature 383: 832-836.

Latinkic, B., M. Umbhauer, K. N eal, W. Lerchner, J. Smith, and V. Cunliffe. 1997. The Xenopus Brachyury promoter is activated by FGF and low concentrations of activin and suppressed by high concentrations of activin and by paired-type homeodomains. Genes \& Dev. 11: 3265-3276.

Laurent, M., I. Blitz, C. Hashimoto, U. Rothbacher, and K. Cho. 1997. The Xenopus homeobox gene twin mediates Wnt in- 
duction of goosecoid in establishment of Spemann's organizer. Development 124: 4905-4916.

Lecuit, T., W. Brook, M. N g, M. Calleja, H. Sun, and S. Cohen. 1996. Two distinct mechanisms for long-range patterning by decapentaplegic in the Drosophila wing. Nature 381: 387393.

Liu, F., A. Hata, J.C. Baker, J. Doody, J. Carcamo, R.M. Harland, and J. Massagué. 1996. A human Mad protein acting as a BMP-regulated transcriptional activator. Nature 381: 620-623.

Liu, F., C. Pouponnot, and J. Massagué. 1997. Dual role of the Smad4/DPC4 tumor suppressor in TGF $\beta$ inducible transcriptional complexes. Genes \& Dev. 11: 3157-3167.

Lo, R., Y. Chen, Y. Shi, N. Pavletich, and J. M assagué. 1998. The L3 Loop: A structural motif determining specific interactions between SM AD proteins and TGF $\beta$ receptors. EMBO J. 17: 996-1005.

Lopez-Casillas, F., J. Wrana, and J. M assagué. 1993. Betaglycan presents ligand to the TGF $\beta$ signaling receptor. Cell 73: 1435-1444.

Lustig, K., K. Kroll, E. Sun, R. Ramos, H. Elmendorf, and M. Kirschner. 1996. A Xenopus nodal-related gene that acts in synergy with noggin to induce secondary axis and notochord formation. Devel opment 122: 3275-3282.

Macias-Silva, M., S. Abdollah, P.A. Hoodless, R. Pirone, L. Attisano, and J.L. Wrana. 1996. Madr2 is a substrate of the Tgf- $\beta$ receptor and its phosphorylation is required for nuclear accumulation and signaling. Cell 87: 1215-1224.

Massagué, J. 1998. TGF $\beta$ signal transduction. Annu. Rev. Biochem. (in press).

Mehler, M., P. M abie, D. Zhang, and J. Kessler. 1997. Bone morphogenetic proteins in the nervous system. Trends N eurosci. 20: 309-317.

Mishina, Y., A. Suzuki, N. Ueno, and R. Behringer. 1995. Bmpr encodes a type I bone morphogenetic protein receptor that is essential for gastrulation during mouse embryogenesis. Genes \& Dev. 9: 3027-3037.

Moses, H.L. and R. Serra. 1996. Regulation of differentiation by TGFB. Curr. Opin. Genet. Dev. 6: 581-596.

Nakao, A., M. Afrakhte, A. Moren, T. N akayama, J. Christian, R. Heuchel, S. Itoh, M. Kawabata, N. Heldin, C. Heldin, and P. ten Dijke. 1997a. Identification of Smad7, a TGF $\beta$ inducible antagonist of tGF $\beta$ signaling. Nature 389: 631-635.

Nakao, A., T. Imamura, S. Souchelnytskyi, M. Kawabata, A. Ishisaki, E. Oeda, K. Tamaki, J.-I. Hanai, C.-H. Heldin, K. Miyazono, and P. ten Dijke. 1997b. TGF $\beta$ receptor mediated signaling through Smad2, Smad3, and Smad4. EMBO J. 16: $5353-5362$.

N akayama, T., M. Snyder, S. Grewal, K. Tsuneizumi, T. Tabata, and J. Christian. 1998. Xenopus Smad8 acts downstream of BM P-4 to modulate its activity during vertebrate embryonic patterning. Development 125: 857-867.

N ellen, D., R. Burke, G. Struhl, and K. Basler. 1996. Direct and long range action of a DPP morphogen gradient. Cell 85: 357-368.

Neubuser, A., H. Peters, R. Balling, and G. Martin. 1997. Antagonistic interactions between FGF and BMP signaling pathways: A mechanism for positioning the sites of tooth formation. Cell 90: 247-255.

N eumann, C. and S. Cohen. 1997. Morphogens and pattern formation. BioEssays 19: 721-729.

N ewfeld, S.J., E.H. Chartoff, J.M. Graff, D.A. M elton, and W.M. Gel bart. 1996. M others against D pp encodes a conserved cytoplasmic protein required in $\mathrm{Dpp} / \mathrm{T}$ gf- $\beta$ responsive cells. Devel opment 122: 2099-2108.

N ewfeld, S., A. M ehra, M. Singer, J. Wrana, L. Attisano, and W.
Gelbart. 1997. M others against dpp participates in a DPP/ TGF $\beta$ responsive serine-threonine kinase signal transduction cascade. Development 124: 3167-3176.

Niki, I., H. Yokokura, T. Sudo, M. Kato, and H. Hidaka. 1996. $\mathrm{Ca} 2+$ signaling and intracellular $\mathrm{Ca} 2+$ binding proteins. J. Biochem. 120: 685-698.

Nishimatsu, S., A. Suzuki, A. Shoda, K. Murakami, and N. Ueno. 1992. Genes for bone morphogenetic proteins are differentially transcribed in early amphibian embryos. Biochem. Biophys. Res. Commun. 186: 1487-1495.

N ishimatsu, S., K. Takebayashi, A. Suzuki, K. Murakami, and $\mathrm{N}$. Ueno. 1993. Immunodetection of Xenopus bone morphogenetic protein-4 in early embryos. Growth Factors 8: 173176.

Niswander, L. and G. Martin. 1993. FGF-4 and BMP-2 have opposite effects on limb growth. Nature 361: 68-71.

N omura, M. and E. Li. 1998. Roles for Smad2 in mesoderm formation, left right patterning, and craniofacial development in mice. Nature 393: 786-789.

Oda, S., S. N ishimatsu, K. Murakami, and N. Ueno. 1995. Molecular cloning and functional analysis of a new activin $b$ subunit: A dorsal mesoderm-inducing acitivity in Xenopus. Biochem. Biophys. Res. Comm. 210: 581-588.

Oft, M., J. Peli, C. Rudaz, H. Schwarz, H. Beug, and E. Reichmann. 1996. TGF- $\beta 1$ and Ha-Ras collaborate in modulating the phenotypic plasticity and invasiveness of epithelial tumor cells. Genes \& Dev. 10: 2462-2477.

Patterson, G., A. Koweek, A. Wong, L. Yanxia, and G. Ruvkun. 1997. The daf-3 smad protein antagonizes TGF- $\beta$-related receptor signaling in the Caenorhabditis el egans dauer pathway. Genes \& Dev. 11: 2679-2690.

Piccolo, S., Y. Sasai, B. Lu, and E. DeRobertis. 1996. Dorsoventral patterning in Xenopus inhibition of ventral signals by binding of chordin to BM P-4. Cell 86: 589-598.

Piccolo, S., E. Agius, B. Lu, S. Goodman, L. Dale, and E.M. DeRobertis. 1997. Cleavage of chordin by Xolloid metalloprotease suggests a role for proteolytic processing in the regulation of Spemann Organizer activity. Cell 91: 407-416.

Raftery, L., V. Twombly, K. Wharton, and W. Gelbart. 1995. Genetic screens to identify elements of the decapentaplegic signaling pathway. Genetics 139: 241-254.

Re'em-Kalma, Y., T. Lamb, and D. Frank. 1995. Competition between noggin and bone morphogenetic protein 4 activities may regulate dorsalization during Xenopus development. Proc. Natl. Acad. Sci. 92: 12141-12145.

Roberts, A.B. and M.B. Sporn. 1993. Physiological actions and clinical applications of transforming growth factor- $\beta$. Growth Factors 8: 1-9.

Rosa, F.M. 1989. Mix.1, a homeobox mRN A inducible by mesoderm inducers, is expressed mostly in the presumptive endodermal cells of Xenopus embryos. Cell 57: 965-974.

Sasai, Y., B. Lu, H. Steinbeisser, D. Geissert, L. Gont, and E.M. De Robertis. 1994. Xenopus chordin: A novel dorsalizing factor activated by organizer-specific homeobox genes. Cell 79: 779-790.

Savage, C., P. Das, A.L. Finelli, S.R. Townsend, C.Y. Sun, S.E. Baird, and R.W. Padgett. 1996. Caenorhabditis el egans genes Sma2, Sma-3, and Sma-4 define a conserved family of transforming growth factor $\beta$ pathway components. Proc. Natl. Acad. Sci. 93: 790-794.

Schmidt, J., V. Francois, E. Bier, and D. Kimelman. 1995a. Drosophila short gastrulation induces an ectopic axis in Xenopus: Evidence for conserved mechanisms of dorsal-ventral patterning. Development 121: 4319-4328.

Schmidt, J.E., A. Suzuki, N. Ueno, and D. Kimelman. 1995b. Localized BM P-4 mediates dorsal/ventral patterning in the 
early Xenopus embryo. Dev. Biol. 169: 37-50.

Schulte-M erker, S., J.C. Smith, and L. Dale. 1994. Effects of truncated activin and FGF receptors and of follistatin on the inducing activities of $\mathrm{BVgl}$ and activin: Does activin play a role in mesoderm induction? EMBO J. 13: 3533-3541.

Sekelsky, J.J., S.J. N ewfeld, L.A. Raftery, E.H. Chartoff, and W.M. Gel bart. 1995. Genetic characterization and cloning of M others against dpp, a gene required for decapentapl egic function in Drosophila melanogaster. Genetics 139: 1347-1358.

Shi, Y., A. Hata, R.S. Lo, J. M assagué, and N .P. Pavletich. 1997. A structural basis for mutational inactivation of the tumour suppressor Smad4. Nature 388: 87-93.

Shibuya, H., H. Iwata, N. M asuyama, Y. Gotoh, K. Yamaguchi, K. Irie, K. Matsumoto, E. N ishida, and N. Ueno. 1998. Role of TAK1 and TAB1 in BMP signaling in early Xenopus development. EMBO J. 17: 1019-1028.

Sirard, C., J.L. de Ia Pompa, A. Elia, A. Itie, C. Mirtsos, A. Cheung, S. Hahn, A. Wakeham, L. Schwartz, S. Kern, J. Rossant, and T. Mak. 1998. The tumor suppressor gene Smad4/ Dpc4 is required for gastrulation and later for anterior devel opment of the mouse embryo. Genes \& Dev. 12: 107-119.

Sive, H.L., K. Hattori, and H. Weintraub. 1989. Progressive detemination during formation of the anteroposterior axis of Xenopus Iaevis. Cell 58: 171-180.

Smith, J.C. 1987. A mesoderm-inducing factor is produced by a Xenopus cell line. Devel opment 99: 3-14.

Souchel nytski, S., K. Tamaki, U. Engstrom, C. Wernstedt, P. ten Dijke, and C.-H. Heldin. 1997. Phosphorylation of $\mathrm{Ser}^{465}$ and $\mathrm{Ser}^{467}$ in the C-terminus of Smad2 mediates interaction with Smad4 and is required for TGF $\beta$ signaling. J. Biol. Chem. 272: 28107-28115.

Steinbach, O., A. Wolffe, and R. Rupp. 1997. Somatic linker histones cause loss of meosdermal competence in Xenopus. Nature 389: 395-399.

Suzuki, A., R.S. Thies, N. Yamaji, J.J. Song, J.M. Wozney, K. Murakami, and N. Ueno. 1994. A truncated bone morphogenetic protein receptor affects dorsal-ventral patterning in the early Xenopus embryo. Proc. N atl. Acad. Sci. 91: 1025510259.

Suzuki, A., C. Chang, J.M. Yingling, X.F. Wang, and A. Hemmati-Brivanlou. 1997a. Smad5 induces ventral fates in Xenopus embryo. Dev. Biol. 184: 402-405.

Suzuki, A., E. Kaneko, N. Ueno, and A. Hemmati-Brivanlou. 1997b. Regulation of epidermal induction by BMP2 and BM P7. Dev. Biol. 189: 112-122.

Tanabe, Y. and T. Jessell. 1997. Diversity and patterning in the developing spinal cord. Science 274: 1115-1122.

Thomsen, G. and D. Melton. 1993. Processed Vgl protein is an axial mesoderm inducer in Xenopus. Cell 74: 433-441.

Thomsen, G.H. 1996. Xenopus mothers against decapentapl egic is an embryonic ventralizing agent that acts downstream of the Bmp-2/ 4 receptor. Development 122: 2359-2366.

Topper, J., J. Cai, Y. Qiu, K. Anderson, Y. Xu, J. Deeds, R. Feel ey, C. Gimeno, E. Woolf, O. Tayber, G. Mays, B. Sampson, F. Schoen, M. Gimbrone, and D. Falb. 1997. Vascular MADs: Two novel MAD-related genes selectively inducible by flow in human vascular endothelium. Proc. Natl. Acad. Sci. 94: 9314-9319.

Tsuneizumi, K., T. N akayama, Y. Kamoshida, T. Kornberg, J. Christian, and T. Tabata. 1997. Daughters against dpp modulates dpp organizing activity in Drosophila wing development. Nature 389: 627-631.

Wal drip, W., E. Bikoff, P. Hoodless, J. Wrana, and E. Robertson. 1998. Smad2 signaling in extraembryonic tissues determines anterior-posterior polarity of the early mouse embryo. Cell 92: 797-808.
Wall, N.A. and B.L.M. Hogan. 1994. TGF- $\beta$ related genes in development. Curr. Biol. 4: 517-522.

Watabe, T., S. Kim, A. Candia, U. Rothbacher, C. Hashimoto, K. Inoue, and K.W.Y. Cho. 1995. M olecular mechanisms of Spemanns organizer formation-Conserved gzrowth factor synergy between Xenopus and mouse. Genes \& Dev. 9: 30383050.

Weeks, D.L. and D.A. Melton. 1987. A maternal mRN A localized to the vegetal hemisphere in Xenopus eggs codes for a growth factor related to TGF- $\beta$. Cell 51: 861-867.

Wharton, K., R. Ray, and W. Gel bart. 1993. An activity gradient of decapentaplegic is required for dorsal-ventral patterning in the Drosophila embryo. Development 117: 807-822.

Wiersdorff, V., T. Lecuit, S.M. Cohen, and M. Mlodzik. 1996. $M$ ad acts downstream of $D$ pp receptors, reveal ing a differential requirement for $\mathrm{Dpp}$ signaling in initiation and propagation of morphogenesis in the Drosophila eye. Development 122: 2153-2162.

Wilson, P.A., G. Lagna, A. Suzuki, and A. Hemmati-Brivanlou. 1997. Concentration-dependent patterning of the Xenopus ectoderm by BM P4 and its signal transducer Smad1. Development 124: 3177-3184.

Winnier, G., M. Blessing, P.A. Labosky, and B.L. Hogan. 1995. Bone morphogenetic protein-4 is required for mesoderm formation and patterning in the mouse. Genes \& Dev. 9: 21052116.

Wisotzkey, R., A. Mehra, D. Sutherland, L. Dobens, X. Liu, C. Dohrmann, L. Attisano, and L. Raftery. 1998. Medea is a Drosophila Smad4 homolog that is differentially required to potentiate DPP responses. Development 125: 1433-1445.

Xu, X., Z. Yin, J. Hudson, E. Ferguson, and M. Frasch. 1998. Smad proteins act in combination with synergistic and antagonistic regulators to target $\mathrm{Dpp}$ responses to the Drosophila mesoderm. Genes \& Dev. 12: 2354-2370.

Yamaguchi, K., K. Shirakabe, H. Shibuya, K. Irie, I. Oishi, N. Ueno, T. Taniguchi, E. Nishida, and K. Matsumoto. 1995. Identification of a member of the MAPKKK family as a potential mediator of TGF- $\beta$ signal transduction. Science 270: 2008-2011.

Yang, X., C. Li, X. Xu, and C. Deng. 1998. The tumor suppressor SM AD4/DPC 4 is essential for epiblast proliferation and mesoderm induction in mice. Proc. Natl. Acad. Sci. 95: 36673672.

Yingling, J., P. Das, C. Savage, C. Xhang, and R. Padgett. 1996. Mammalian dwarfins are phosphorylated in response to TGF $\beta$ and are implicated in the control of cell growth. Proc. Natl. Acad. Sci. 93: 8940-8944.

Yingling, J., M. Datto, C. Wong, J. Frederick, N. Liberati, and X. Wang. 1997. Tumor suppressor Smad4 is a transforming growth factor inducible DNA binding protein. Mol. Cell. Biol. 17: 7019-7028.

Zawel, L., J. Dai, P. Buckhaults, S. Zhou, K. Kinzler, B. Vogelstein, and S. Kern. 1998. Human Smad3 and Smad4 are sequence specific transcription activators. Mol. Cell 1: 611-617.

Zhang, Y., X.H. Feng, R.Y. Wu, and R. Derynck. 1996. Receptorassociated $\mathrm{M}$ ad homologues synergize as effectors of the Tgf- $\beta$ response. Nature 383: 168-172.

Zhang, Y., T. M usci, and R. Derynck. 1997. The tumor suppressor Smad4/DPC 4 as a central mediator of Smad function. Curr. Biol. 7: 270-276.

Zimmerman, C., M. Kariapper, and L. Mathews. 1998. Smad proteins physically interact with calmodulin. J. Biol. Chem. 273: $677-680$.

Zimmerman, L.B., L.M. De Jesus-Escobar, and R.M. Harland. 1996. The Spemann organizer signal noggin binds and inactivates bone morphogenetic protein 4. Cell 86: 599-606. 


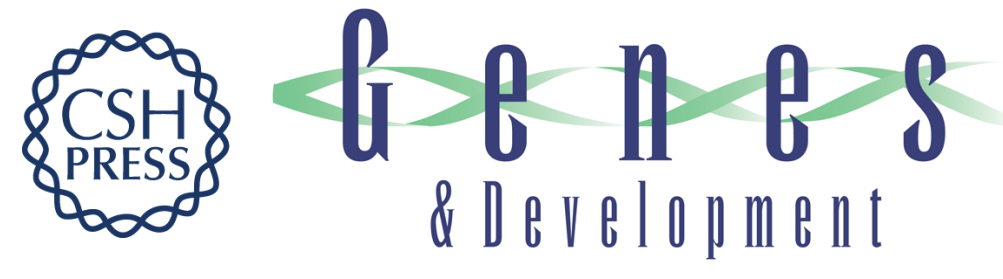

\section{Smads and early developmental signaling by the TGF $\beta$ superfamily}

Malcolm Whitman

Genes Dev. 1998, 12:

Access the most recent version at doi:10.1101/gad.12.16.2445

\section{License}

Email Alerting Receive free email alerts when new articles cite this article - sign up in the box at the top Service right corner of the article or click here.

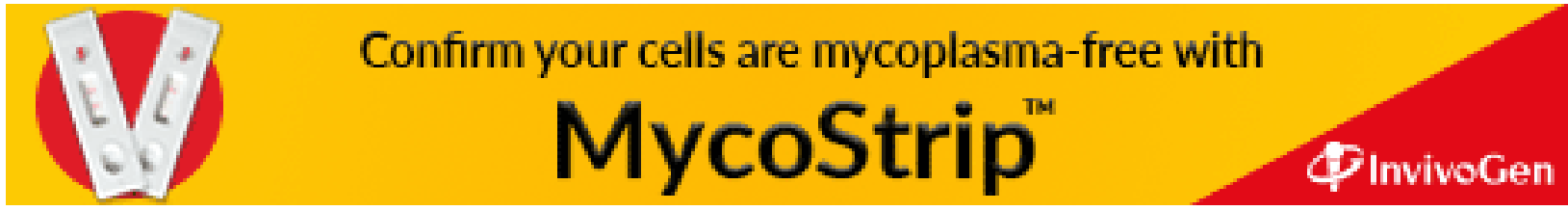

